\title{
Are available models reliable for predicting the FRP contribution to the shear resistance of RC beams?
}

\author{
Gabriel Sas ${ }^{1}$, Björn Täljsten ${ }^{2}$, Joaquim Barros ${ }^{3}$, João Lima ${ }^{4}$, and Anders Carolin ${ }^{5}$
}

\begin{abstract}
In this paper the trustworthiness of the existing theory for predicting the FRP contribution to the shear resistance of reinforced concrete beams is discussed. The most well-known shear models for EBR (External Bonded Reinforcement) are presented, commented on and compared with an extensive experimental database. The database contains the results from more than 200 tests performed in different research institutions across the world. The results of the comparison are not very promising and the use of the additional principle in the actual shear design equations should be questioned. The large scatter between the predicted values of different models and experimental results is of real concern bearing in mind that some of the models are used in present design codes.
\end{abstract}

Subject headings: Bearing capacity; Concrete beams; Fiber reinforced polymers; Shear strength; State-of-theart reviews.

\section{Introduction}

Shear strengthening of reinforced concrete (RC) beams using fiber reinforced polymers (FRP) has been studied intensively in the last decade, even if shear for simple reinforced concrete beams is not actually fully understood. The design equations for reinforced concrete beams used in the main current design guidelines are based on semi empirical approaches, e.g. ACI 318-05 (2005) and Eurocode 2 (2004). The shear capacity of the beams is computed by adding the contribution of the concrete $\left(V_{c}\right)$ and the steel stirrups $\left(V_{s}\right)$. In most of the cases, using the same procedure, the shear strength of the RC beams strengthened with composite materials is computed by adding the contribution of the FRP $\left(V_{f r p}\right)$. While the empirical design equations for reinforced concrete beams

\footnotetext{
${ }^{1}$ PhD Student, Department of Civil, Mining and Environmental Engineering, Division of Structural Engineering, Luleå University of Technology SE-971 87 Luleå, Sweden, Email: gabriel.sas@,1tu.se

${ }^{2}$ Professor Department of Civil, Mining and Environmental Engineering, Division of Structural Engineering, Luleå University of Technology SE-971 87 Luleå, Sweden, Email: björn.täljsten@1tu.se. Department of Civil Engineering, ${ }^{3}$ Technical University of Denmark, Brovej Building 118, 2800 Kgs. Lyngby, Denmark, Email: bt@byg.dtu.dk Associate Professor, ISISE, Dep. Civil Eng., School Eng., University of Minho, Campus de Azurém, 4800-058 Guimarães, Portugal, Email: barros@civil.uminho.pt

${ }^{4}$ MSc Student, ISISE, Dep. Civil Eng., School Eng., University of Minho, Campus de Azurém, 4800-058 Guimarães, Portugal, Email: joao_lima@netcabo.pt

${ }^{5}$ Lecturer, Department of Civil, Mining and Environmental Engineering, Division of Structural Engineering, Luleå University of Technology, SE-971 87 Luleå, Sweden, Email: anders.carolin@ltu.se
} 
were validated with extensive experimental results, the equations for predicting the shear resistance of FRP strengthened RC beams are often compared with a small number of experiments, and, in some cases, using test series of questionable rigor. Three main configurations of FRP strengthening may be used for externally bonded reinforcement (EBR): side bonding, U-wrapping and complete wrapping (ACI Committee 440 2002; fib Task Group 9.3 2001), see Figure 1. The near surface mounted reinforcement (NSMR) has been also used for shear strengthening (Dias and Barros 2008) but the application is limited to side bonding technique.

The development of theoretical models began using the assumption that FRP materials behave like internal stirrups. Later, studies were focused on developing new theories based on the real strain field distribution. Even if a large effort has been focused on theoretical studies, the shear strength models are almost as many as the research studies performed.

Chaallal et al. (1998) proposed the equation for calculating the shear contribution of FRP based on the assumption that the composite and the stirrups behave similarly.

Malek and Saadatmanesh (1998a, b) introduced in their formulation the anisotropic behavior of the FRP. Studies have revealed that the inclination angle of the critical shear crack is influenced by the plate thickness, FRP percentage and orientation angle, percentage of existing steel hoops, concrete quality and percentage and diameter of the tensile longitudinal steel bars.

A model, obtained by experimental fitting, was derived by Triantafillou (1998), and Triantafillou and Antonopoulos (2000). The contribution of the FRP is limited by the effective strain in the composite. Further on, Khalifa et al. (1998, 1999) modified Triantafillou's (1998) model introducing strain limitations due to shear crack opening and loss of aggregate interlock. The proposed model was appraised by considering more tests.

By combining the strip method and shear friction approach Deniaud and Cheng $(2001,2003)$ stated that the FRP strains are uniformly distributed among the fibers crossing the critical shear crack. A design model was developed based on the failure mechanism observed on the tested specimens. The evaluation showed a good agreement between model predictions and test results. A refined model was proposed later by Deniaud and Cheng (2004). 
Continuing the Khalifa model, Pellegrino and Modena (2002) suggested a modified reduction factor for the ratio of the effective strain to ultimate strain in FRP. According to the experimental studies performed, the stiffness ratio between transversal shear reinforcement and FRP shear reinforcement has a significant effect on the effectiveness of shear strengthening. Available information is restricted to side-bonded beams strengthening configurations. Aspects regarding lateral concrete peeling failure under shear loading of FRP were studied later by Pelegrino and Modena (2006). The model of these authors follows the truss model approach and describes the concrete, steel and FRP contribution to the shear capacity of RC beams based on the experimental observations. Carolin (2003) and Carolin and Täljsten (2005) proposed an equation to predict the contribution of EBR composites for the shear strengthening, limiting the tensile failure of the fiber. The non-uniform distribution of the strains in FRP over the cross section was stated. A 55\% to $65 \%$ of the maximum measured strain value was recommended for engineering design. The equations are used today in the Swedish Design Guideline for FRP strengthening (Täljsten, 2006).

Chen and Teng (2003a, b, 2004) analyzed the shear failure of the reinforced concrete beams strengthened with FRP and concluded that the stress distribution in the FRP along the crack plane is non-uniform. They proposed a model for reinforced concrete beams strengthened with FRP that takes into account the fiber rupture and debonding failure modes. The model also assumes a non-uniform stress distribution in the FRP along the shear crack. Stress limitation is introduced by bond length coefficient and strip width coefficient.

Using an adapted compression field theory, Ianniruberto and Imbimbo (2004) developed a theoretical model to predict the contribution of FRP sheets for the shear capacity of RC beams. Although the authors have made a coherent derivation, the model has some limitations, since it can be used only for wrapping strengthening schemes; hence it is not prepared to predict debonding failure mechanism for side bonding and U configurations. Furthermore, the model does not simulate the strain concentration at the composite-crack intersection, so the potential rupture in the composite at cracking regions cannot be captured. Theoretical predictions were compared with experimental results and, unfortunately found to be incompatible.

Adhikary et al. (2004) proposed two equations to determine the shear strength of CFRP and ARFP strengthened RC beams, calibrating the model proposed by Triantafillou (1998). These authors suggested that the two 
proposed equations should be checked with other test results available in the literature, since the effective strain in FRP was not yet clearly defined, and depends on many factors.

Introducing some adjustments to the model of Chen and Teng (2003b), Cao et al. (2005) proposed an empirical model to predict the FRP contribution to the shear strengthening of RC beams strengthened with complete wrapping of FRP strips failing by FRP debonding. The strain distribution modification factor gave uncertain results due to the large scatter of the test data. The comparison of the theoretical prediction with the experimental results has shown "a general agreement between the two" with "a significant scatter".

The shear bond model proposed by Zhang and Hsu (2005) followed two approaches: model calibration by curve fitting and bond mechanism. The smallest reduction factor for the effective strain obtained from the two methods was suggested to be used.

The model for the shear debonding strength developed by Ye et al. (2005) has its theoretical starting point in Chen and Teng's model, and it is being used in the Chinese Design Code.

Monti and Liotta (2006) proposed a debonding model for the FRP-based shear strengthening of RC beams. The features of the model are divided in three steps: a) generalized constitutive law of FRP layer bonded to concrete, b) boundary limits - function of the strengthening scheme and shear crack opening provisions, c) stress field in the FRP crossing a shear crack, analytically determined. A generalized failure criterion of FRP strips/sheets is introduced. Two cases are considered: straight strip/sheet and strip/sheet wrapped around a corner. This model is currently used in the Italian design code CRN (2005).

\section{Database description}

A full database containing 211 experiments (Table 1), collected by Lima and Barros (2007), was used to compare the theoretical predictions of the FRP contribution to shear. Nevertheless more experiments have been performed in the period covered by this research program, they were not included in this database since critical parameters are missing in their description. The database contains values from experiments performed on 34 beams with $\mathrm{T}$ cross sections and 177 beams with rectangular cross sections. The most used strengthening configuration was the U-wrapped with 101 elements, from which 6 include mechanical anchorages. From the 
remaining 110 beams, 72 were side-bonded without any mechanical anchorages. The other 38 identified beams were fully wrapped. The beams containing different anchorage systems are considered in the present study only for the models that are addressing specifically a theoretical approach for strengthening system with anchorages. Most of the available theoretical models do not simulate the effect of the anchorage systems and, consequently, failure predictions are unrealistic. In this case the beams considering anchorage systems are removed from the comparison. The specimens having dimensions smaller than $100 \times 200 \mathrm{~mm}$ were also removed from the comparison, since due to the scale effect, the obtained results might be not representative of the real behavior of FRP-based shear strengthened beams. The effective anchorage length of the FRP has been determined to be approximately 200-250mm (Täljsten 1994, Brosens and van Gemert, 1997), hence sufficient anchorage length cannot be assured in shallow beams, resulting in an inefficient strengthening. Furthermore, beams with inappropriate material characteristics reported, i.e. of too low strength concrete, were also removed. The minimum value of the concrete compressive strength considered was $12 \mathrm{MPa}$.

\section{Bases of comparison}

After removing the beams from the database that did not correspond to the above criteria, the theoretical predictions of the models will be plotted for each model. The capacity of the RC beams has not been considered in the comparison because the models presented in the studied literature refer only to the composite contribution to the total capacity. The experimental values of the FRP contribution have been obtained by subtracting the values obtained from the tests on reference beams from the values obtained from the FRP strengthened beams. For calculating the predictions of each individual model the materials properties obtained from tests and reported in the original papers have been considered. However, for two models (Monti and Liotta, 2007 and Ye et al., 2005) the characteristic compressive strength and the design tensile strength of concrete are required. These values have been determined based on the EC2 (2004) recommendations. No partial safety factors have been adopted in the calculations of the predictions.

\section{Shear models predictions}


Even if the strengthening method has been used for more than a decade, the main part of the theoretical research has been focused on the flexural behavior of strengthened elements. Research on shear behavior has not been studied to the same extent. The shear models presented below are the models most commonly used in practical design. An exception from this rule was made for models introduced in national design guidelines, since they have a greater use in practical design.

For the theoretical predictions the models, in general, assume that shear failure crack has a $45^{\circ}$ inclination angle, but experimental works have shown that this inclination can vary between 30 to 60 degrees, depending on the parameters already mentioned (Carolin, 2003).

The researchers define the contribution of the FRP to the shear strength as the product between the effective stress in FRP, the area of the FRP, partial reduction factors that intend to take into account the quality of material and/or workmanship quality, and a geometrical factor depending on the type of strengthening system used, as well as fiber inclination with respect to the beams longitudinal axis. In general, the scientists are in agreement about the type and relevance that these parameters have in the prediction performance of a model, but the way that these parameters are defined is not the same, and relatively important differences can be found. The main differences appear on the evaluation of the stresses/strains in fibers. Based on the method of analysis, two different types of constitutive models have been proposed: empirical and semi empirical.

In a previous work, Lima and Barros (2007), based on the results of the same database, had already verified that none of the fib (2001), ACI (2002), CNR (2005) and CIDAR (2006) analytical formulations predicts with enough accuracy the contribution of the EBR CFRP systems for the shear strengthening of RC beams. In the present work this type of appraisal is extended to a larger set of models, published in reputed journals and conference proceedings.

The models presented in this section are used to calculate the contribution of the FRP only for the strengthening configurations for which they were devised. A plot representing the shear contribution of the fibers for rectangular beams and $\mathrm{T}$ beams is presented for each model for a better visualization and a realistic evaluation of the results by the reader. For the sake of simplicity all the equations are presented using the same notation. A detailed notation list is appended at the end of the paper. 


\section{Chaallal (1998)}

The proposed equation for calculating the shear contribution of FRP assumes that composites stirrups have similar functioning principle, Eq. (1). The model assumes that the FRP tensile strength is reached when the composite is intersected by the shear crack, as long as sufficient bond length is guaranteed. When the model was derived the non-uniform distribution of the stresses over the cross section of the beam was not stated by any researcher, making this assumption unrealistic.

$$
V_{f i p}=2\left[\tau_{\text {avg }}\left(\frac{b_{f i p} h_{f r p}}{2}\right)\right] \frac{(\sin \beta+\cos \beta) d}{s_{f r p}}
$$

The debonding problem is treated in a simplified form using the average shear stress (Eq. (2) between the FRP and concrete, even if the authors were aware of the non uniform distribution of the stresses.

$$
\tau_{\text {avg }}=\frac{1}{2} \tau_{\max }^{\text {debonding }}
$$

where $\tau_{\max }^{\text {debonding }}$ is the maximum shear stress given by:

$$
\tau_{\max }^{\text {debonding }}=\frac{5.4}{1+k_{1} \tan 33^{\circ}} \text { and } k_{1}=t_{f r p}\left[\frac{k_{n}}{4 E_{f r p} I_{f r p}}\right]^{1 / 4} \text { with } k_{n}=E_{a} b_{a} / t_{a}
$$

The use of the average shear stress may be interpreted as: if sufficient bond length is assured then the tensile strength of FRP can be fully mobilized. Actually, the stress level will not increase by increasing the bond length if the effective bond length was already provided. The accuracy of this model cannot be checked since the values of the thickness and strength of the adhesive in parameter $k_{1}$ are not reported in most of the experimental studies presented in the database (Table 1).

\section{Triantafillou (1998) and Triantafillou and Antonopoulos (2000)}

According to Triantafillou (1998), and Triantafillou and Antonopoulos (2000), an accurate estimation of the FRP contribution to the shear capacity is quite difficult to obtain, due to the influence that too many factors has on the failure mode. The formulation is based on the Eqs. (4, (5 and (6):

$V_{f r p}=\frac{0.9}{\gamma_{f r p}} \rho_{f r p} E_{f r p} \varepsilon_{f r p, e} b_{w} d(1+\cot \beta) \sin \beta$ 


$$
\begin{array}{ll}
\varepsilon_{f i p, e}=0.0119-0.0205 \rho_{f i p} E_{f r p}+0.0104\left(\rho_{f i p} E_{f i p}\right)^{2} & 0 \leq \rho_{f i p} E_{f i p} \leq 1 \\
\varepsilon_{f i p, e}=-0.00065 \rho_{f i p} E_{f i p}+0.00245 & \rho_{f i p} E_{f i p}>1
\end{array}
$$

The model was derived using the truss analogy based on a semi - quantitative approach. The key parameter of the analytical expression, $\varepsilon_{f i p, e}$, was obtained from regression of experimental data of beam tests, which may suggest a narrow coverage solution for the shear problem. This effective strain has been found dependent both on the axial rigidity of the composite and effective bond length, and is used as the minimum of: maximum strain to control crack opening, strain limiting due to debonding, and strain corresponding to shear failure combined or followed by FRP rupture.

At that moment no clear distinction was made between the different types of strengthening on the application of the formula. The research was then extended, using a larger data base of available test reports (Triantafillou and Antonopoulos 2000). The model evolved still based on the regression analysis, but with a specifically defined effective strain for detailed failure types, different strengthening schemes and materials, Eqs. (7, (8 and (9).

- Wrapped with CFRP

$$
\varepsilon_{f i p, e}=0.17 \varepsilon_{f i p, u}\left(\frac{f_{c}^{2 / 3}}{E_{f i p} \rho_{f i p}}\right)^{0.30}
$$

- $\quad \mathrm{U}$ - shaped CFRP jackets

$$
\varepsilon_{f p p, e}=\min \left[0.65\left(\frac{f_{c}^{2 / 3}}{E_{f p p} \rho_{f p p}}\right)^{0.56} \times 10^{-3} ; 0.17 \varepsilon_{f p p, u}\left(\frac{f_{c}^{2 / 3}}{E_{f p p} \rho_{f p p}}\right)^{0.30}\right]
$$

- Wrapped with AFRP

$$
\varepsilon_{f i p, e}=0.048 \varepsilon_{f i p, u}\left(\frac{f_{c}^{2 / 3}}{E_{f i p} \rho_{f p p}}\right)^{0.47}
$$

However, this model cannot simulate the FRP effective strain of the side bonding shear strengthening configuration, which is a limitation of its use. Due to the limited data available at the moment of the model's derivation, its prediction accuracy is unsatisfactory, but the similar distribution around the bisector can point out regression as being an acceptable method for deriving a viable model (Fig. 2). 
Khalifa et al. (1998) and Khalifa and Nanni (2000)

Based on the Triantafillou model (1998), Khalifa et al. (1998) recommended a modified effective strain both for fiber rupture and debonding failure. A similar equation of the FRP contribution to the shear strength to the one of Triantafillou (1998) was derived (Eq. (10).

$$
V_{f r p}=\frac{A_{f r p} f_{f r p, e}(\sin \beta+\cos \beta) d_{f r p}}{s_{f r p}} \text { where } f_{f r p, e}=R f_{f r p, u}
$$

The effective stress in fibers was established as a function of FRP stiffness, and ultimate strain is obtained by regression of experimental data Eq. (11). The equation is valid only for CFRP continuous sheets or strips and is suitable if the failure mechanism is controlled by FRP sheet rupture. The effective ratio is limited at $R \leq 0.5$.

$$
R=0.5622\left(\rho_{f r p} E_{f r p}\right)^{2}-1.2188 \rho_{f r p} E_{f r p}+0.778
$$

Since Eq. (11) is not valid for debonding mechanism, the effective stress/strain $R$ factor was derived considering a bond mechanism model (Eq. (12).

$$
R=\frac{\left(f_{c}\right)^{2 / 3} w_{f r p, e}}{\varepsilon_{f r p, u} d_{f r p}}\left[738.93-4.06\left(E_{f r p} t_{f r p}\right)\right] \times 10^{-6}
$$

The real width of the FRP, $w$, was replaced by an effective width $w_{f r p, e}$ (Eqs. (13 and 14) to account for the several effects, such as: shear crack angle (assumed to be $45^{\circ}$ ); effective bond and configuration of the strengthening, i.e. wrapped, U-jacketing or side bonded. The effective length proposed by Maeda (1997) was adopted in this case (Eq. 15). Due to its empirical deduction and the lack of test data at that moment, the effective bond length is limited to the value of $75 \mathrm{~mm}$ proposed by Miller (1999), and Khalifa and Nanni (2000).

$$
\begin{gathered}
w_{f r p, e}=d-L_{e} \text { for U-jacketing } \\
w_{f r p, e}=d-2 L_{e} \text { for side bonding } \\
L_{e}=e^{6.134-0.58 \ln \left(t_{f r p} E_{f f p}\right)}
\end{gathered}
$$

Finally, a reduction factor of 0.7 for the FRP contribution to the shear capacity is prescribed. This model can be considered as the first complete formulation of the CFRP shear design strengthening, since it considers all three 
main types of strengthening configurations. Like in Triantafillou (1998), and Triantafillou and Antonopoulos (2000) models, this one presents the same weaknesses due to its empirical nature (Fig. 3).

\section{Chen and Teng model (2001 and 2003a, b)}

An extensive work performed by Chen and Teng (2001 and 2003a, b) resulted in one of the most widely-used shear models. The general equation (16) is based on the truss model theory, with the remark that discrete FRP strips were modeled as equivalent continuous FRP sheets/plates and a reduction factor for the stress is used instead of strain, as in the previous models. Since the authors of the model considered continuous sheets as a special case of strips, the equations of Chen and Teng's models are established in terms of strips.

$$
V_{f i p}=2 f_{f i p, e} t_{f r p} w_{f i p} \frac{d_{f i p}(\cot \theta+\cot \beta) \sin \beta}{s_{f i p}}, \text { where } f_{f i p, e}=D_{f i p} \sigma_{f p p, \max }
$$

The average stress of the FRP intersected by the shear crack, $f_{f i p, e}$, is determined based on the assumption that stress distribution in the FRP along the shear crack is not uniform at the ultimate limit state for both rupture and debonding failure modes. The key factors of the model are considered to be the stress distribution factor, $D_{f i p}$, and the maximum stress that can be reached in the FRP intersected by the shear crack, $\sigma_{f r p, \max }$. The stress distribution factor is determined for both failure modes by integrating the stresses or strains over the cross section (Eq. (17).

$$
D_{f i p}=\frac{\int_{z_{t}}^{z_{b}} \sigma_{f r p, z} d z}{d_{f r p} \sigma_{f r p, \max }} \text { or }=\frac{\int_{z_{t}}^{z_{b}} \varepsilon_{z} d z}{d_{f r p} \varepsilon_{\max }}
$$

\section{FRP Rupture}

Different shapes of non linear distribution of the strains over the crack are considered in the model similar to the approach found in Carolin (2003). For a general strengthening scheme, the stress distribution has been expressed as a dimensionless factor (Eq. (18) depending on geometrical boundary conditions (Eqs. (19 and (20).

$$
D_{f i p}=\frac{1+\zeta}{2}, \text { where } \zeta=\frac{z_{t}}{z_{b}}
$$


$z_{t}=\left(0.1 d+d_{f r p, t}\right)-0.1 d=d_{f r p, t} \quad$ is the coordinate of the top end of the effective FRP

$z_{b}=\left[d-\left(h-d_{f r p}\right)\right]-0.1 d \quad$ is the coordinate of the bottom end of the effective FRP

When fiber rupture occurs, the maximum stress in the FRP is considered to be the ultimate tensile strength. The Authors advised that, due to the loss of aggregate interlocking, the ultimate tensile failure of the fiber may be reached before the shear failure of the beam has being attained.

\section{FRP Debonding}

The debonding model developed by Chen and Teng (2003b) considers "an effective bond length beyond which an extension of the bond length cannot increase the bond strength" of utmost importance. The maximum stress in the FRP at debonding is considered to be:

$$
\sigma_{f r p, \max }=\min \left\{\begin{array}{l}
f_{f r p, u} \\
0.427 \beta_{w} \beta_{L} \sqrt{\frac{E_{f r p} \sqrt{f_{c}}}{t_{f r p}}}
\end{array}\right.
$$

By analyzing the model one can notice the unit inconsistency of the maximum stress expressed in this mathematical form. The reason might be considered the fracture mechanic approach and regression analysis on the ultimate bond strength and the FRP width ratio (Chen and Teng, 2001). The two coefficients $\beta_{L}, \beta_{w}$ (Eqs. (22a and (22b) reflect the effective bond length and the effect of FRP to concrete width ratio, respectively,

$$
\text { (a) } \beta_{L}=\left\{\begin{array}{cc}
1 & \text { if } \lambda \geq 1 \\
\sin \left(\frac{\pi \lambda}{2}\right) & \text { if } \lambda<1
\end{array}\right\} ; \text { (b) } \beta_{w}=\sqrt{\frac{2-w_{f r p} /\left(s_{f r p} \sin \beta\right)}{1+w_{f r p} /\left(s_{f r p} \sin \beta\right)}}
$$

The normalized maximum bond length parameter, $\lambda$, the maximum bond length, $L_{\max }$, and the effective bond length, $L_{e}$, are given as:

$$
\lambda=\frac{L_{\max }}{L_{e}} ; L_{\max }=h_{f r p, e} / \sin \beta \text { for U jacketing, } L_{\max }=h_{f r p, e} /(2 \sin \beta) \text { for side bonding and } L_{e}=\sqrt{\frac{E_{f r p} t_{f r p}}{\sqrt{f_{c}}}}
$$

In this model it was assumed that all the FRP crossing the shear crack can develop full bond strength. Under this assumption, the stress distribution factor for debonding failure was derived (Eq. (24a). It must be noted as 
equally important that the bond strength of a strip depends on the distance from the shear crack relative to the ends of the strip. For design purposes a simplified formula was suggested (Eq. (24b) in which $95 \%$ characteristic bond strength given by the analytical model is used. The plot of the theoretical predictions versus the experimental values from the database is presented in Fig. 4. The prediction of the FRP shear contribution shows a large scatter, in several cases drastically underestimating or overestimating the capacity for rectangular beams. The $T$ beams show a fairly safe prediction, but a conclusion cannot be drawn due to lack of sufficient experimental data.

$$
\text { (a) } D_{f i p}=\left\{\begin{array}{l}
\frac{2}{\pi \lambda} \frac{1-\cos \frac{\pi}{2} \lambda}{\sin \frac{\pi}{2} \lambda} \text { if } \lambda \leq 1 \\
1-\frac{\pi-2}{\pi \lambda} \text { if } \lambda>1
\end{array}\right\} ; \text { (b) } \sigma_{f i p, \max }=\min \left\{\begin{array}{l}
0.8 f_{f p p} / \gamma_{f i p} \\
\frac{0.3}{\gamma_{b}} \beta_{w} \beta_{L} \sqrt{\frac{E_{f i p}}{t_{f i p}} \sqrt{f_{c}}}
\end{array}\right.
$$

\section{Deniaud and Cheng model (2001 and 2004)}

The model proposed by Deniaud and Cheng (2001, and 2004) has its origins in the modified friction method as a combination of Loov's (1998) shear friction method for RC beams and a strip method for computing the contribution of FRP strips. It must be noted the different approach used for concrete and steel contributions in Eq. (25). A different crack pattern is used for flange and web of the T beam, which might lead to a more accurate prediction of the total shear capacity. The FRP contribution, determined according to Eq. (26), is directly included in the expression that evaluates the total shear capacity of a beam (Eq. (25). Therefore, the comparison is carried out in terms of total shear capacity. The last term of represents the contribution of FRP sheets in the case of U-jacketing configuration. When discrete strips are used the FRP contribution can be computed from (Deniaud and Cheng 2001).

$$
\begin{gathered}
V=k \sqrt{f_{c} A_{c}\left(T_{v}+T_{f r p}\right) \frac{d_{s}}{s}}-T_{v} \\
T_{f r p}=d_{f r p} t_{f i p} E_{f r p} \varepsilon_{f r p, e} R_{L}\left(\frac{w_{f p p}}{s_{f r p}}\right)^{2}\left(\frac{\mathrm{s}}{d_{s}} \sin \beta+\cos \beta\right) \sin \beta
\end{gathered}
$$


The method consists of an iterative procedure of evaluating the shear capacity of the beam with all potential crack patterns. The continuous debonding of the FRP is tracked until the maximum load is reached. The method is using an experimental curve for the interface shear stress from which the bond strength and the maximum allowable strain was determined. Based on experimental observations, linear and uniform distribution of the load among the fiber was considered. The effective bond length is calculated according to the Eq. (15), initially proposed by Maeda et al. (1997).

Assuming that the ultimate load does not increase after the specified effective length, Deniaud and Cheng (2004) investigated in depth the shear stress field at the interface between concrete and FRP, and proposed a curve to determine the maximum bond strength. The factor accounting for the concrete bond shear resistance, $v=0.23$, was obtained by fit regression evaluated at $\mathrm{L} / \mathrm{Le}=1$. As a function of the available effective length, the shear stress, $\tau$, can be determined according to Eqs. (27a and (27b).

$$
\frac{\tau}{\sqrt{f_{c}}}=\left(2-\frac{L}{L_{e}}\right) \nu \text { when } L<L_{e} \text { and } \frac{\tau}{\sqrt{f_{c}}}=\frac{L}{L_{e}} v \text { when } L \geq L_{e}
$$

Large discrepancies and scattering between different interfaces shear strength curves proposed in literature and Deniaud and Cheng's interface shear strength curve were found.

By regression and using the strip method the equation (28) was obtained that can determine the maximum FRP strain for sheets side bonded and beams "wrapped underneath the web".

$$
\varepsilon_{\max }=\frac{3 \sqrt{f_{c}} d_{f i p}^{0.16}}{\left(t_{f i p} E_{f i p}\right)^{0.67}\left(k_{a} \sin \beta\right)^{0.1}}(\%)
$$

The remaining bonded width over initial width ratio was determined in a similar way as for the maximum strain, i.e. regression (Eq. (29):

$$
R_{L}=1-1.2 \exp \left[-\left(\frac{d_{f i p}}{k_{e} L_{e f f} \sin \alpha}\right)^{0.4}\right]
$$

Given that the model has been derived based on a regression analysis with RC beams reinforced with steel stirrups, only these specimens found in the database have been used in the comparison. For this model, the degree of safe predictions is higher than for most of the other models for both $\mathrm{T}$ and rectangular beams (Fig. 5), 
but with a high degree of scattering. One of the reasons may be the incompatibility of the effective length adopted from Maeda (1997) with the modified friction method.

\section{Adhikary et al. model (2004)}

After a series of tests with RC beams strengthened with $\mathrm{U}$ - wrapped and $\mathrm{U}$ - wrapped with different anchorage lengths on top of the beam, Adhikary et al. proposed two equations to predict the contribution of CFRP and AFRP systems for the shear resistance of RC beams. The effective strain when debonding occurs is evaluated by Eqs. (30a and (30b) that were defined by calibrating Triantafillou and Antonopoulos model (2000) with data available in the literature.

$$
\text { (a) } \frac{\varepsilon_{f i p, e 1}}{\varepsilon_{f i p, u}}=\frac{0.038 f_{c}^{\frac{1}{3}}}{\sqrt{\rho_{f p p} E_{f i p}}} \text { for CFRP; (b) } \frac{\varepsilon_{f i p, e 1}}{\varepsilon_{f i p, u}}=\frac{0.034 f_{c}^{\frac{1}{3}}}{\sqrt{\rho_{f i p} E_{f r p}}} \text { for AFRP }
$$

The second equation of the model takes into account "the bonded anchorage provided to the top of the surface of the beam". It can be assumed that this quote refers to a provided mechanical anchorage, since no other specifications are given in the paper. The effective strain in the FRP is assumed to increase due to this anchorage, so, in this case the effective strain at failure is the sum of the effective strain in the FRP in the debonding mode $\varepsilon_{f e l}$ and the increase in effective strain in FRP due to bond anchorage $\varepsilon_{f r p, e 2}$.

$$
\text { (a) } \frac{\varepsilon_{f i p, e}}{\varepsilon_{f i p, u}}=\frac{0.038 f_{c}^{\frac{1}{3}}}{\sqrt{\rho_{f i p} E_{f i p}}}+0.0043 \times f_{c}^{\frac{2}{3}} \text { for CFRP; (b) } \frac{\varepsilon_{f i p, e}}{\varepsilon_{f i p, u}}=\frac{0.034 f_{c}^{\frac{1}{3}}}{\sqrt{\rho_{f i p} E_{f i p}}}+0.0046 \times f_{c}^{\frac{2}{3}} \text { for AFRP }
$$

Eqs. (31a and (31b) can be interpreted as: the effective strain at debonding when mechanical anchorages are used is the sum of the effective strain at debonding from Eqs. (30a and (30b), and an empirically determined value of the concrete strength.

Adhikary et al. (2004) considered their proposed equations as valid only for the case when the axial rigidity is in the interval $0<\rho_{f r p} E_{f r p} \leq 1.0$, since for larger values of the axial rigidity the scatter of the collected data used for the calibration gave unsafe predictions.

To compute the shear contribution provided by FRP bonded sheets, Adhikary proposed the Eq. (32). 


$$
V_{f r p}=\rho_{f r p} E_{f r p} \varepsilon_{f r p} d_{f r p} b_{w}(\sin \beta+\cos \beta)
$$

Since Adhikary et al. (2004) derived the model based on experiments performed on rectangular cross section beams, the results on $\mathrm{T}$ cross section strengthened beams have not been included in the comparison. Apart the beams with $U$ wrapping and $U$ wrapping with anchorage strengthening configurations, the remaining beams were not considered in this study. The comparison for the model proposed by Adhikary et al. (2004) is presented in Fig. 6. It is hard to formulate a clear conclusion because the model refers to a limited amount of comparable values.

\section{Ye et al. model (2005)}

The model for the shear debonding strength developed by Ye et al. (2005) has its theoretical starting point in Chen and Teng's model (2003 a, b), and it has been proposed in the Chinese Design Code. The FRP contribution to the shear capacity is obtained from Eq. (16), replacing $f_{f r p, e}$ by $\varepsilon_{f r p, e} E_{f}$. Here the simplified proposal of Lu (2004, by Ye et. al) for the average FRP strain $\varepsilon_{f r p, e}$ when debonding is a dominant failure mode (Eq. (33) has been adopted.

$\varepsilon_{f r p, e}=k_{v} \varepsilon_{f r p, i n f}$ with $k_{v}=\left\{\begin{array}{lc}0.77\left(1-e^{-\lambda / 0.79}\right) & \text { for side plates } \\ 0.96\left(1-e^{-\lambda / 0.62}\right) & \text { for U jacketing }\end{array}\right.$

A new formulation of the bond length ratio $\lambda$ (Eq. (34) is expressed in this model, as the ratio of the FRP effective bond height, $h_{f r p, e}$, to the FRP effective bond length $L_{e}$ :

$$
\lambda=\frac{h_{f r p, e}}{2 L_{e} \sin \beta} \text { and } L_{e}=1.33 \frac{\sqrt{E_{f r p} t_{f r p}}}{f_{t}}
$$

A new term is introduce in this model, the FRP strain for an infinite bond length, $\varepsilon_{f, i n f}$, which is determined from Eq. (35). Compared to Chen and Teng's equation (Eq. (21) this term does not account for the bond length coefficient, but it is obtained in the same way, by regression analysis.

$$
\varepsilon_{f, \text { inf }}=\beta_{w} \sqrt{\frac{0.616 \sqrt{f}}{E_{f r p} t_{f r p}}} \text { with } \beta_{w}=\sqrt{\frac{2.25-w_{f r p} / s_{f r p}}{1.25+w_{f r p} / s_{f r p}}}
$$


In the equation that evaluates the contribution of the FRP for the shear resistance of RC beams (Eq. (36), an inclination angle of $45^{\circ}$ was assumed for the critical crack, and the average bond strength between the FRP and concrete is directly taken into account.

$V_{f i p}=\psi_{v} K_{f} \tau w_{f i p} \frac{h_{f i p, e}^{2}(\sin \beta+\cos \beta)}{s_{f i p}}$ where $K_{f}=\phi_{f i p} \frac{\sin \beta \sqrt{E_{f i p} t_{f i p}}}{\sin \beta \sqrt{E_{f i p} t_{f i p}}+0.3 h_{f i p, e} f_{t}}$ and $\tau=1.2 \beta_{w} f_{t d}$

Ye et al. (2005) compared the model with the experimental results. Predictions were considered to be in good agreement with test data and conservative. When compared with the larger database the predictions (Fig. 7) follow a safe trend, but still with a wide scatter.

\section{Cao et al. model (2005)}

Cao et al. (2005) proposed a simple model to predict the contribution of FRP to the shear capacity of beams where "complete debonding of the critical strips occurs". This model is also based on the previous work performed by Chen and Teng (2003a, b), and is intended to improve the strain distribution factor $D_{f r p}$ for discrete strips. The general definition proposed by Chen and Teng (2003 b) in Eq. (17) was adopted and expressed as the average strain in all FRP strips divided by the maximum strain (Eq. (37).

$$
D_{f r p}=\frac{\sum_{i=1}^{n} \varepsilon_{f r p, i}}{n \varepsilon_{f r p, \max }} \approx \frac{\int_{0}^{l} \varepsilon_{f r p}(x) d x}{l \varepsilon_{f r p, \max }}
$$

The model requires strain measurements (for the maximum strain and to determine the average strain, "which are mostly dependent on the test errors") in the strips intersected by the shear crack. The average and maximum strains along the critical shear crack were also determined by regression analysis, taking the discrete strain observations.

Eq. (24a), proposed by Chen and Teng (2003b), was refined considering the effect of the shear span-to-effective depth ratio on the strain distribution factor $D_{f i p}$. Cao et al. (2005) admitted that the modified Eq. (38) does not really improve the theoretical predictions compared with the test data.

$$
D_{f i p}=\left(1-\frac{\pi-2}{\pi \lambda_{f i p}}\right)(1.2-0.1 \lambda) \text { for } 1.4<\lambda<3
$$


In order to estimate the contribution of FRP to the shear resistance at debonding, the interaction between the shear span-to-effective depth ratio and the critical shear crack angle was analyzed, resulting in the following equation:

$$
D_{f \theta}=\left(1-\frac{\pi-2}{\pi \lambda_{f r p}}\right) \times \begin{cases}1 & \text { for } \lambda \leq 1.4 \\ \frac{1}{1-0.2(\lambda-1.4)^{2}} & \text { for } 1.4<\lambda<3 \\ 2.05 & \text { for } \lambda \geq 3\end{cases}
$$

Furthermore, the maximum strain in the FRP at debonding was analyzed, and an equation similar to the one proposed by Ye et al. (2004) was determined (Eq. (40).

$$
\varepsilon_{f i p, \max }=0.427 \beta_{w} \frac{\sqrt{f_{c} L_{e}}}{E_{f i p} t_{f i p}}=0.427 \beta_{w} \frac{\sqrt[4]{f_{c}}}{\sqrt{E_{f i p} t_{f r p}}}
$$

From the comparison of the theoretical predictions of the Cao et al. (2005) model with the experimental results of the collected data base, depicted in Fig. 8, a significant scatter and unsafe predictions were obtained.

\section{Zhang and Hsu model (2005)}

The shear bond model proposed by Zhang and Hsu (2005) was derived in two steps: model calibration by curve fitting and bond mechanism. The smallest reduction factor, obtained using the two methods, was suggested to be used for the evaluation of the effective strain.

\section{Curve fitting model}

To determine the reduction factor for the evaluation of the effective strain when debonding failure occurs, the initial model proposed by Khalifa et al. (1998) was used (see Eq. (12).

Having collected more data from test results, the authors used a power regression line to determine the reduction factor, $R$. The power regression gave higher R-square values than the polynomial, which led to the conclusion that the power regression line gives a more realistic prediction of the FRP contribution (Eq. (41a)

(a) $R=0.1466\left(\rho_{f r p} E_{f r p}\right)^{-0.8193}$; (b) $R=1.8589\left(\rho_{f r p} E_{f r p} / f_{c}\right)^{-0.7488}$ 
Separate analysis was performed for the debonding and fiber rupture failure modes. A large scatter between the two failure modes was observed. Fiber rupture occurred at $0<\rho_{f p p} E_{f i p}<0.55 \mathrm{GPa}$, while debonding occurred at $0<\rho_{f i p} E_{f i p}<1.2$ GPa. Zhang and Hsu (2005) concluded that debonding dominates over the tensile rupture of the CFRP laminates as they become thicker and stiffer, thus the effective strain needs to be consequently reduced. According to Zhang and Hsu (2005) the effective strain in fibers is influenced by the concrete strength, i.e. when concrete strength increases the effective strain increases too. Based on the influence of the concrete strength another model was derived, also adopting a power regression line to evaluate the reduction factor (Eq. (41b). The new reduction factor was obtained by dividing the axial rigidity to the concrete compressive strength. The new model was considered to have better results in terms of R-square, when compared to the results obtained using the other reduction factors.

\section{Bond mechanism model}

Proposed for design purposes, the model uses a triangular shape distribution of the shear stresses. Using a simple equilibrium equation for the pure shear stress transfer (not including normal stresses) the total force that can be transferred on two sides is computed according to Eq. (42a). The force when the beam fails in shear failure is given in Eq. (42b). Applying the equilibrium condition for the two equations the strain (stress) reduction factor is determined (Eq. (42c).

(a) $T=\frac{1}{2} \cdot \tau_{\max } \cdot L_{e} \cdot\left(2 \cdot w_{f i p, e}\right)$; (b) $T=2 \cdot t_{f i p} \cdot w_{f p p, e} \cdot f_{f p p e,} ;$ (c) $R=\frac{f_{f i p, e}}{f_{f i p, u}}=\frac{\tau_{\max } \cdot L_{e}}{2 \cdot t_{f i p} \cdot f_{f i p, u}} \leq 1$

The effective bond length, $L_{e}$, of the FRP sheets was proposed to be $75 \mathrm{~mm}$.

The maximum shear stress was computed as a best-fit polynomial function of the concrete compressive strength (Eq. (43).

$$
\tau_{\max }=\left(7.64 \cdot 10^{-4} \cdot f_{c}^{2}\right)-\left(2.73 \cdot 10^{-2} \cdot f_{c}\right)+6.38
$$

Aware of the empirical nature of the model, Zhang and Hsu (2005) suggested adjustments to the model when more experimental data are available. The comparisons plot (Fig. 9) shows a large scatter of the predicted values, but slightly safer than the previous models. 


\section{Carolin (2003) and Carolin and Täljsten (2005)}

The design model is based on the superposition principle of the shear contributions of the strengthening and the strut and tie model. A calibration factor to consider the non uniform strain distribution over the cross section, derived by Popov (1998) was proposed. This factor, $\eta$, expresses the average strain in the fibers over the height of the beam in relation to the strain in the most stressed fiber (Eq. (44).

$$
\eta=\frac{\int_{-h / 2}^{h / 2} \varepsilon_{f r p}(y) d y}{\varepsilon_{f r p, \max } \cdot h}
$$

The factor includes the relative stiffness between concrete in compression, cracked reinforced concrete in tension and lightly reinforced concrete in tension. The proposed design model by Carolin and Täljsten (2005) is given in Eq. (45)

$$
V_{F R P}=\eta \cdot \varepsilon_{c r} \cdot E_{f r p} \cdot t_{f r p} \cdot r_{f r p} \cdot z \cdot \frac{\sin (\theta+\beta)}{\sin \theta}
$$

The critical strain, $\varepsilon_{c r}$ (Eq. (46a), is limited by a minimum value of the ultimate allowable fiber capacity, $\varepsilon_{f r p, u l t}$, the maximum allowable strain without achieving anchorage failure $\varepsilon_{\text {bond }}$ (Eq. (46b), and maximum allowable strain to achieve concrete contribution, $\varepsilon_{c, \max }$, e.g. concrete contribution due to aggregate interlocking.

$$
\text { (a) } \varepsilon_{c r}=\min \left\{\begin{array}{l}
\varepsilon_{f r p, u} \\
\varepsilon_{b o n d} \cdot \sin ^{2}(\theta+\beta) \\
\varepsilon_{c, \max } \cdot \sin ^{2}(\theta+\beta)
\end{array}\right\} \text {, (b) } \varepsilon_{b o n d}=\frac{1}{E_{f r p} t_{f r p}} \sqrt{2 E_{f r p} t_{f r p} G_{f}} \begin{cases}\sin \left(\omega L_{c r}\right) \text { for } L_{c r} \leq \frac{\pi}{2 \omega} \\
1 \quad \text { for } L_{c r}>\frac{\pi}{2 \omega}\end{cases}
$$

In Eq. (46b) $G_{f}$ is the concrete fracture energy and $\omega$ is defined as in Täljsten (1994):

$$
\omega=\sqrt{\frac{\tau_{\max }^{2}}{2 \cdot E_{f r p} \cdot t_{f r p} \cdot G_{f}}}
$$

The reduction of $\sin ^{2}(\theta+\beta)$ to the anchorage and concrete contribution comes from the anisotropic behavior of the composite. If the concrete contribution is not included in the shear bearing capacity the limiting parameter $\varepsilon_{c, \max }$ can be ignored. The critical strain times the reduction factor gives the effective strain, $\varepsilon_{f r p, e}$, described 
earlier. The $r_{f r p}$ factor in Eq. (45) depends on the layout of the strengthening system and is given in Eqs. (48a and (48b):

(a) $r_{r f p}=\sin \beta$ for continuous wrapping; (b) $r_{f r p}=\frac{w_{f i p}}{s_{f i p}}$ for discrete strips

When the theoretical predictions are compared to the experimental results (Fig. 10) a safer estimation of the FRP contribution to shear capacity is found but still with a large scatter. The cause of this might be the definition of fracture energy of concrete, which is still a challenge for the research, since it is not clear which fracture mode is dominant, i.e. fracture mode I, fracture mode II, fracture mode III or a combination of both.

\section{Monti and Liotta (2007)}

A complete design method was developed by Monti and Liotta (2008) considering all the strengthening schemes and failure modes known at that time. The model was derived by considering the three following main aspects: a) a generalized FRP-concrete bond constitutive law is defined; b) boundary limitations are considered; and c) the stress field in the FRP crossing a shear crack is analytically determined. Also the following assumptions are considered: the cracks are evenly spaced along the beam axis with an inclination of $\theta$, the crack depth is equal to the internal lever arm $z=0.9 d$ for the ultimate limit state, the resisting shear mechanism is based on the truss analogy for wrapping and U-jacketing. For side bonding, the development of a "crack-bridging" resistance mechanism was considered, due to the missing tensile diagonal tie in the truss analogy. The last two assumptions yield that, for wrapping and U-jacketing the truss resisting mechanism can be activated, while for side bonding the role of the FRP is that of "bridging the crack". The effective bond length (Eq. (49) and the debonding strength are defined for side bonding (Eq. (50).

$$
\begin{gathered}
L_{e}=\sqrt{\frac{E_{f i p} t_{f p p}}{2 f_{c t m}}} \\
f_{f p, d d}=\frac{0.80}{\gamma_{f i p}} \sqrt{\frac{2 E_{f i p} \Gamma_{F k}}{t_{f i p}}} \text { where } \Gamma_{F k}=0.03 k_{b} \sqrt{f_{c} f_{c t m}} \text { and } k_{b}=\sqrt{\frac{2-w_{f i p} / p_{f p p}}{1+w_{f i p} / 400}} \geq 1
\end{gathered}
$$


When sufficient bond length $\left(l_{b}\right)$ can not be provided due to the strengthening scheme and the apparent shear crack alignment, the bond strength is reduced according to Eq. (51).

$$
f_{f i p, d d}\left(l_{b}\right)=f_{f i p, d d} \frac{l_{b}}{L_{e}}\left(2-\frac{l_{b}}{L_{e}}\right)
$$

According to the authors knowledge, Monti and Liota (2007) were the first researchers to introduce a reduction coefficient considering the radius of the corner of the beam when U-jacketing and wrapping is used (Eq. (52).

$$
\phi_{R}=0.2+1.6 \frac{r_{c}}{b_{w}} \text { for } 0 \leq \frac{r_{c}}{b_{w}} \leq 0.5
$$

The ultimate strength of the FRP for all types of strengthening is defined using the following function:

$$
f_{f r p, u l t}\left(l_{b}, \delta_{e}, r_{c}\right)=f_{f i p, d d}\left(l_{b}\right)+\left\langle\varphi_{R} \cdot f_{f i p, u l t}-f_{f r p, d d}\left(l_{b}\right)\right\rangle \cdot \delta_{e}
$$

If the term in $\longleftrightarrow \cdot$ of this function becomes negative it should be considered null. Also, a generalized stress-slip constitutive function, $\sigma_{f p}\left(u, l_{b}, \delta_{e}\right)$, was proposed. The stress-slip law is denoted as a function of the applied slip, $u$, at the loaded end of the available bond length, $l_{b}$, and the end restraint, $\delta_{e}$. To define the crack width a coordinate system was proposed with the origin placed at the tip of the shear crack and with the abscissa axis along the shear crack. In this way, the crack width, $w$, can be considered perpendicular to the crack axis. The crack opening is considered to be governed by a linear relationship depending on the crack opening angle and distance of the strip/sheet to the crack tip:

$$
w(x)=\alpha \cdot x
$$

Symmetry, with respect to the coordinate system defined above, is considered at both sides of the crack to impose a slip to the FRP. The slip function is given as:

$$
u(\alpha, x)=\frac{w(x)}{2} \sin (\theta+\beta)=\frac{1}{2} \alpha x \sin (\theta+\beta)
$$

Boundary conditions are imposed as a function of the strengthened scheme adopted, i.e. side bonding, $\mathrm{U}$ jacketing or wrapping. With the compatibility (crack width) and boundary conditions, the stress profile in the FRP along the crack $\sigma_{f p p, e}(x)$ is determined. In order to determine the FRP contribution to the shear capacity an effective stress along the shear crack length $z / \sin \theta$ is defined by: 


$$
\sigma_{f p p, e}(\alpha)=\frac{1}{z / \sin \theta} \int_{0}^{z / \sin \theta} \sigma_{f p p, c r}\left[u(\alpha, x), l_{b}(x)\right] d x
$$

The effective debonding strength, $f_{f r p, e d}$, is given by Eqs. (57a, (57b and (58) for side bonding, for U-jacketing, and for wrapping, respectively. The geometrical reduction factor is introduced according to equation (59).

$$
\begin{gathered}
\text { (a) } f_{f i p, e d}=f_{f i p, d d} \frac{z_{\text {rid,eq }}}{\min \left\{0.9 d, h_{w}\right\}}\left(1-0.6 \sqrt{\frac{l_{e q}}{z_{\text {rid }, e q}}}\right)^{2} ; \text { (b) } f_{f i p, e d}=f_{f i p, d d}\left(1-\frac{1}{3} \cdot \frac{L_{e} \sin \beta}{\min \left\{0.9 d, h_{w}\right\}}\right) \\
f_{f i p, e d}=f_{f i p, d d}\left(1-\frac{1}{6} \frac{L_{e} \sin \beta}{\min \left\{0.9 d, h_{w}\right\}}\right)+\frac{1}{2}\left(\phi_{R} f_{f i p, u}-f_{f i p, d d}\right)\left(1-\frac{L_{e} \sin \beta}{\min \left\{0.9 d, h_{w}\right\}}\right) \\
z_{\text {rid,eq }}=\min \left\{0.9 d, h_{w}\right\}-\left(l_{e}-\frac{s_{f}}{f_{f i p, d d} / E_{f i p}}\right) \sin \beta
\end{gathered}
$$

The FRP contribution to the shear capacity is computed considering two approaches: the Mörsch resisting mechanism for $\mathrm{U}$ jacketing and wrapped strengthening schemes computed according to Eq. (60a), while for side bonding, the "bridging" of the shear crack principle is used (Eq. (60b).

$$
\text { (a) } V_{f r p}=\frac{1}{\gamma_{f i p}} 0.9 d \cdot f_{f i p, e d} 2 t_{f r p}(\cot \theta+\cot \beta) \frac{w}{p_{f i p}} ; \text { (b) } V_{f i p}=\frac{1}{\gamma_{f i p}} \min \left\{0.9 d, h_{w}\right\} f_{f r p, e d} 2 t_{f p p} \frac{\sin \beta}{\sin \theta} \frac{w}{p_{f i p}}
$$

The predictive performance of the model was originally appraised using results from an experimental program composed of beams manufactured with a concrete of too low compressive strength. When applied to the collected data base, Fig. 11 shows that the model generally allows safety estimations, but the safety factor is too high and it seems to increase with the increase of the contribution of the FRP shear strengthening configurations.

\section{Conclusions}

The prediction of the shear resistance of RC beams is still a big challenge in structural engineering domain. This complexity is even augmented when FRP materials are used to increase the shear capacity of RC beams. Therefore, it is not strange that differences are observed between the available models for the prediction of the FRP contribution to the shear resistance of RC beams, as well as the use of several and distinct parameters, which, in general, were calibrated from a reduced amount of experimental results. This can partially justify the 
distinct predictive performance of these models, as well as the large dispersion observed when the analytical results determined from these models were compared to results of the biggest data base collected up to the moment in this topic.

Scientists focused their attention on the properties of the composites when deriving the equations, but it is quite clear that existing shear models for FRP strengthening, at least in their present form, do not predict the shear failure very well. From the literature it can also be found that many researchers have calibrated their models from unrealistic geometric conditions on their laboratory specimens. If calibration of experimental results should be done, it is suggested that a Round Robin test procedure should be followed.

Another important concern is the fact that a major part of the experimental programs is composed of rectangular cross section beams, in spite of the fact that $\mathrm{T}$ cross section beams represent the real situation.

The theoretical approach for the $\mathrm{T}$ beams is treated as a special case of the rectangular beams with bonded fibers over a fraction of the cross section. It is also of concern that in some cases theoretical work on $\mathrm{T}$ beams has been validated with experimental data obtained from rectangular cross sections. This direction can be misleading since the two types of cross section have different behavior. One model, as the authors are aware of, considers the interaction between the existing steel stirrups and the FRP wrap (Pellegrino and Modena, 2006), however, since critical parameters to determine the shear contribution of the FRP are missing it was not included in the comparison.

Consequently, before a more thorough understanding of FRP shear strengthened beams has been obtained, a conservative approach is suggested. The question is now how to proceed from here. A well planned International Round Robin test with $\mathrm{T}$ cross section beams, where the main factors that influence this structural problem are carefully considered, seems to be the right path to define a well accepted formulation to predict the contribution of FRP configurations for the shear resistance of RC beams. The quality of monitoring systems (in particular, the ones for measuring the strains in the FRP) and correct evaluation of the properties of the intervening materials need to have a strict control.

\section{Acknowledgments}


The first, the second and the fifth authors wishes to acknowledge the financial assistance of the European Union for the Marie Curie Research Training Network En-Core.

The third and fourth authors wish to acknowledge the support provided by the research program "SmartReinforcement - Carbon fiber laminates for the strengthening and monitoring of reinforced concrete structures" supported by ADI-IDEIA, Project n 13-05-04-FDR-00031.

\section{Notation List}

$A_{c f} \quad=$ effective flange concrete area

$A_{c, p} \quad=$ area of peeled concrete

$A_{\mathrm{cw}} \quad=$ concrete web area

$A_{f r p} \quad=$ area of FRP shear reinforcement

$D_{f i p} \quad=$ the stress distribution factor in FRP

$D_{f i p, \theta} \quad=$ modified distribution factor in FRP accounting the shear crack angle

$E_{a} \quad=$ Young's modulus of the adhesive

$E_{f r p} \quad=$ Young's modulus of the FRP

$I_{f r p} \quad=$ moment of inertia of the FRP plate

$L_{c r} \quad=$ critical bond length

$L_{e} \quad=$ effective bond length

$L_{f} \quad=$ active length of FRP

$G_{f} \quad=$ fracture energy of concrete

$R \quad=$ ratio of effective stress or strain in FRP to its ultimate strength or elongation

$R_{c k} \quad=$ concrete characteristic cube strength

$R_{L} \quad=$ remaining bonded length over initial length ratio

$T \quad=$ force transferred by FRP

$T_{v} \quad=$ tension force in the stirrups

$W_{f r p} \quad=$ width of FRP 


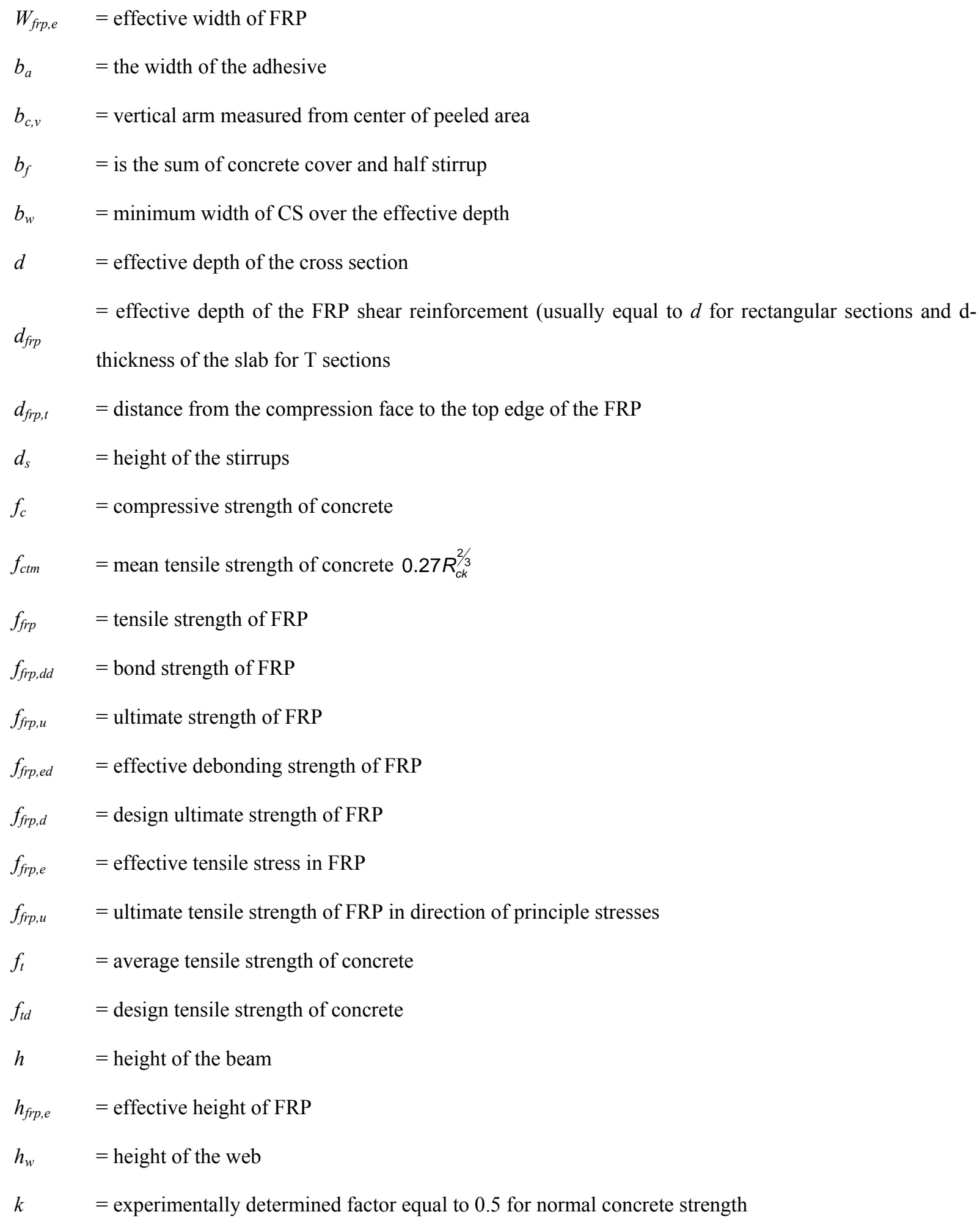




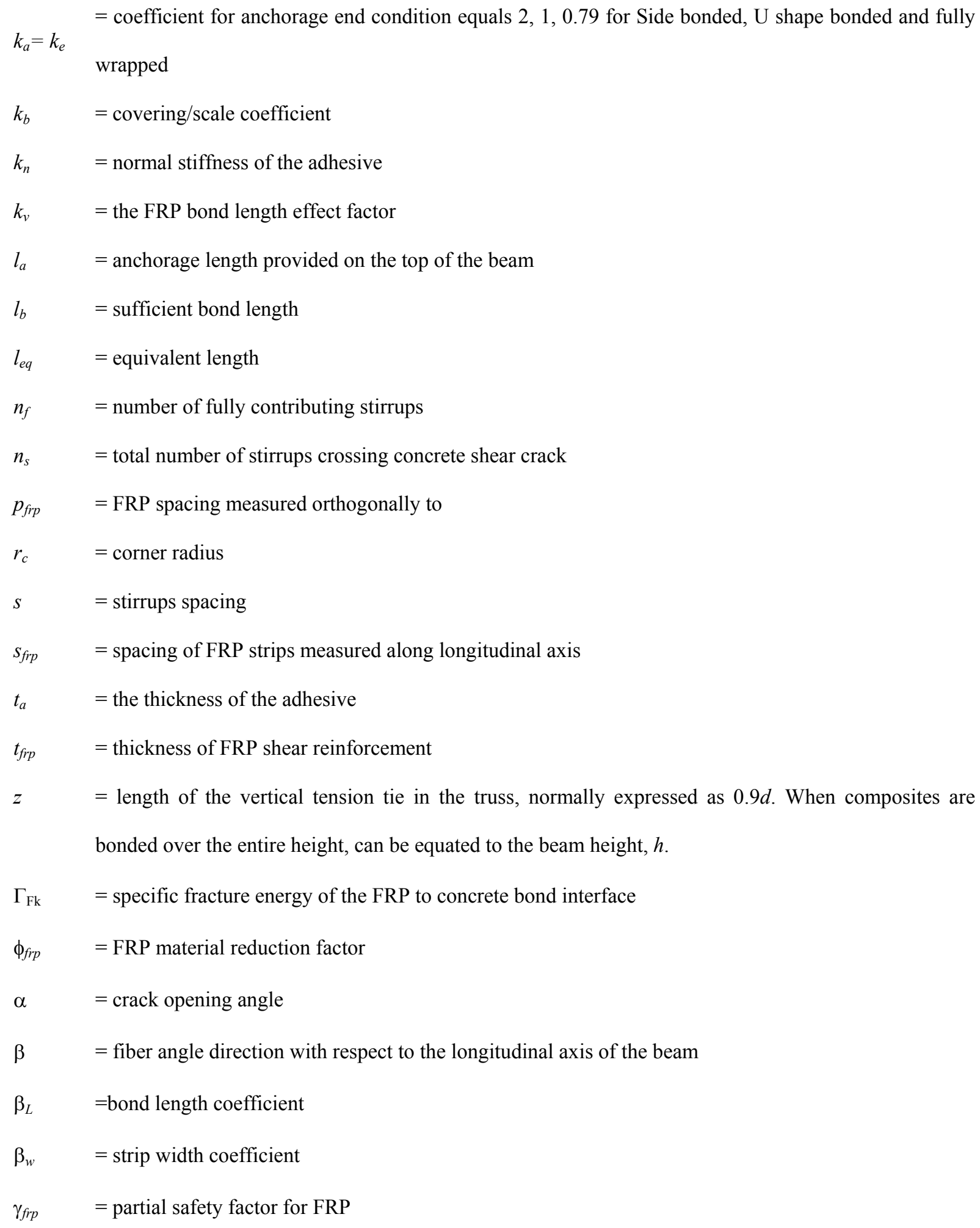




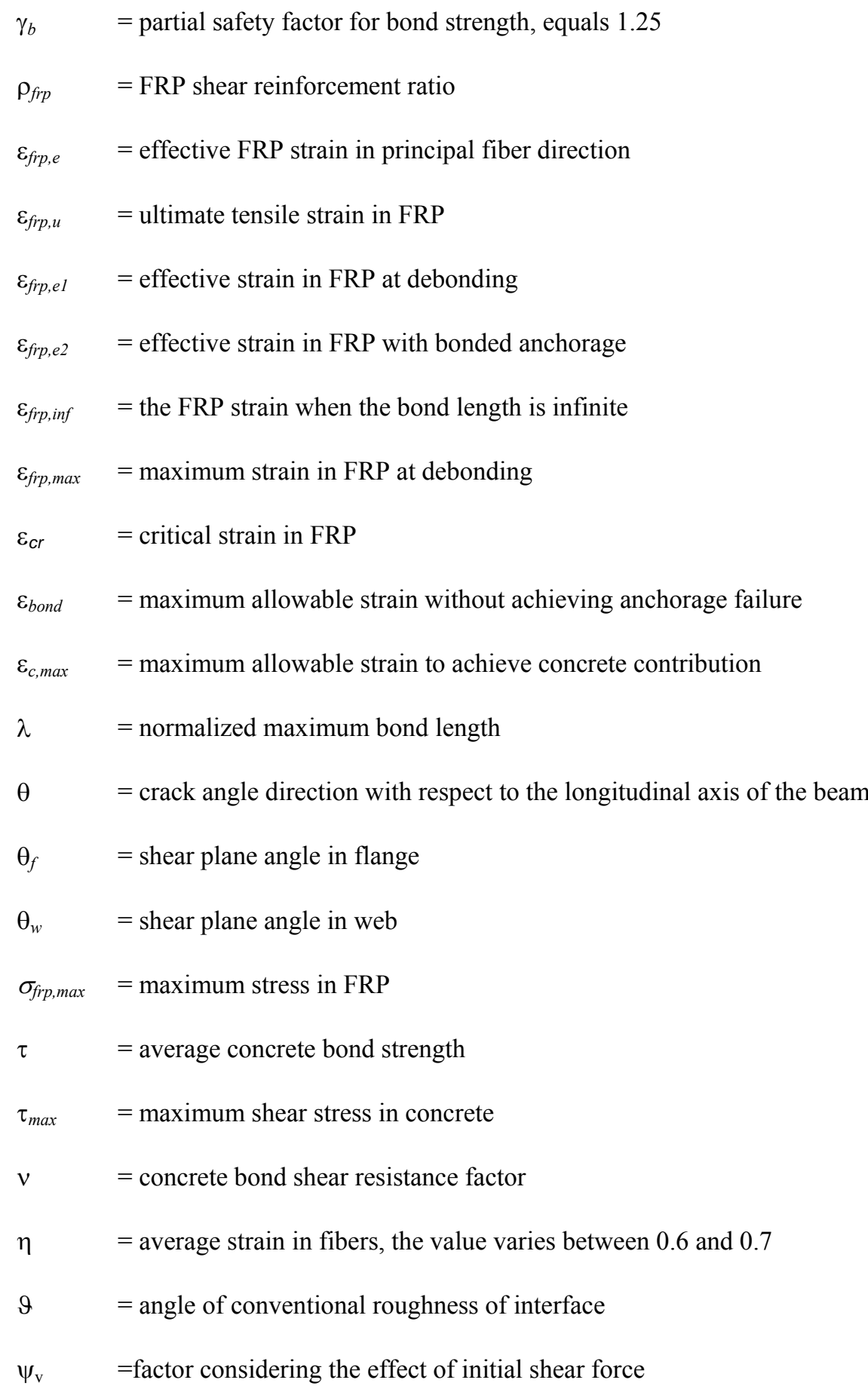

\section{References}


ACI Committee 318 (2005). "Building code requirements for structural concrete (ACI 318-05) and commentary (318R-05).” American Concrete Institute, Farmington Hills, Mich., pp 430.

ACI Committee 440 (2002). "Guide for the design and construction of externally bonded FRP systems for strengthening concrete structures (ACI 440.2R-02)." American Concrete Institute, Farmington Hills, Mich., pp 45.

Adhikary, B. B., Mutsuyoshi, H., and Ashraf, M. (2004). "Shear strengthening of reinforced concrete beams using fiber-reinforced polymer sheets with bonded anchorage.” ACI Struct. J., 101(5), 660-668.

Brosens, K., and van Gemert, D. (1997). "Anchoring stresses between concrete and carbon fibre reinforced laminates." Non-Metallic (FRP) Reinforcement for Concrete Struct., Proc., 3rd Int. Symp., Japan Concrete Institute, Sapporo, 1, 271-278.

Cao, S. Y., Chen, J. F., Teng, J. G., Hao, Z., and Chen, J. (2005). "Debonding in RC beams shear strengthened with complete FRP wraps.” J. Compos. Constr., 9(5), 417-428.

Carolin, A. (2003) "Carbon fiber reinforced polymers for strengthening of structural elements", Doctoral thesis 2003:18, Luleå University of Technology.

Carolin, A., and Täljsten, B. (2005). "Theoretical study of strengthening for increased shear bearing capacity." $J$. Compos. Constr., 9(6), 497-506.

Chaalla,1 O., Nollet, M-J., and Perraton, D. (1998). "Strengthening of reinforced concrete beams with externally bonded fibre-reinforced-plastic plates: design guidelines for shear and flexure." Can. J. Civ. Eng., 25, 692-708. Chen, J. F., and Teng, J. G. (2001). “Anchorage strength models for FRP and steel plates bonded to concrete.” $J$. Struct. Engrg., 127(7),784-791.

Chen, J. F. and Teng, J. G. (2003a). "Shear capacity of fibre-reinforced polymer-strengthened reinforced concrete beams: fibre reinforced polymer rupture.” J. Struct. Engrg., 129(5), 615-625.

Chen, J. F., and Teng, J. G. (2003b) "Shear capacity of FRP-strengthened RC beams: FRP debonding." Constr. Build. Mater., 17, 27-41.

CIDAR (2006). "Design guideline for RC structures retrofitted with FRP and metal plates: beams and slabs" Draft 3 - submitted to Standards Australia, The University of Adelaide. 
CNR (2005). "Instructions for design, execution and control of strengthening interventions through fiberreinforced composites." CNR-DT 200/04, Consiglio Nazionale delle Ricerche, Rome, Italy (English version). Deniaud, C., and Roger Cheng, J. J. "(2001). "Shear behaviour of reinforced concrete T-beams with externally bonded fibre-reinforced polymer sheets." ACI Struct. J., 98(3), 396-394.

Deniaud, C., and Roger Cheng, J. J. (2004). "Simplified shear design method for concrete beams strengthened with fibre reinforced polymer sheets.” J. Compos. Constr., 8( 5), 425-433.

Dias, S.J.E.; Barros, J.A.O., "Shear strengthening of $\mathrm{T}$ cross section reinforced concrete beams by near surface mounted technique", Journal Composites for Construction, 12(3), 300-311, Maio/Junho, 2008.

European Standard EN 1992 (2004), "Eurocode 2: Design of concrete structures", European Committee for Standardization, B-1050 Brussels.

fib Task Group 9.3, 2001, "Externally bonded FRP reinforcement for RC Structures." fib Bulletin 14, Lausanne, Switzerland.

Ianniruberto, U., and Imbimbo, M. (2004). "Role of fibre reinforced plastic sheets in shear response of reinforced concrete beams: Experimental and analytical results." J. Compos. Constr., 8(5), 415-424.

Khalifa, A., Gold, W., Nanni, A., and Abdel Aziz, M. J. (1998). "Contribution of externally bonded FRP to shear capacity of RC flexural members." J. Compos. Constr., 2(4), 195-202.

Khalifa, A., and Nanni, A. (1999). "Improving shear capacity of existing RC T-section beams using CFRP composites." Cement and Concrete Composites, 22( 3), 165-174.

Lima, J. L. T., and Barros, J. A. O. (2007)"Design models for shear strengthening of reinforced concrete beams with externally bonded FRP composites: a statistical vs reliability approach", Proceedings FRPRCS-8, Patras, Greece, July 16-18 (CD ROM).

Loov, R. E. (1998). "Review of A23.3-94 simplified method of shear design and comparison with results using shear friction". Canadian Journal of Civil Engineering, 25, pp. 437-450.

Malek, A. M., and Saadatmanesh, H. (1998a). “Analytical study of reinforced concrete beams strengthened with web bonded fibre reinforced plastic plates or fabrics.” ACI Struct. J., 95(3), 343-352. 
Malek, A. M. and Saadatmanesh, H. (1998b). "Ultimate shear capacity of reinforced concrete beams strengthened with web-bonded fibre reinforced plastic plates.” ACI Struct. J., 95( 4), 391-399.

Miller, B.D. (1999). "Bond between carbon fiber reinforced polymer sheets and concrete." MSc Thesis, Department of Civil Engineering, The University of Missouri, Rolla, MO.

Monti, G., and Liotta, M’A. (2007). "Tests and design equations for FRP-strengthening in shear.” Constr. Build. Mater., 21, 799-809.

Pellegrino, C., and Modena, C. (2002). "Fiber reinforced polymer shear strengthening of reinforced concrete beams with transverse steel reinforcement.” J. Compos. Constr., 6(2), 104-111.

Pellegrino, C., and Modena, C. (2006). "Fibre-reinforced polymer shear strengthening of reinforced concrete beams: Experimental study and analytical modeling.” ACI Struct. J., 103(5), 720-728.

Popov, E. G. (1998). Engineering mechanics of solids, second edition, Prentice Hall, ISBN 0-13-726159-4.

Täljsten, B. (1994). "Plate bonding: Strengthening of existing concrete structures with epoxy bonded plates of steel or fibre reinforced plastics.” Doctoral thesis, Luleå University of Technology, Sweden.

Täljsten, B. (1997). "Defining anchor lengths of steel and CFRP plates bonded to concrete", Int. J. Adhes. Adhes., 17, No. 4, 319-327.

Täljsten, B. (2006) "FRP strengthening of existing concrete structures.” Design guideline fourth edition, ISBN 91-89580-03-6.

Täljsten, B. (2003). "Strengthening concrete beams for shear with CFRP sheets.” Constr. Build. Mater., 17, 1526.

Triantafillou, T. C. (1998). "Shear strengthening of reinforced concrete beams using epoxy-bonded FRP composites.” ACI Struct. J., 95(2), 107-115.

Triantafillou, T. C., and Antonopoulos, C. P. (2000). "Design of concrete flexural members strengthened in shear with FRP.” J. Compos. Constr., 4(4), 198-205.

Teng, J. G., Chen, J. F., Smith, S. T., and Lam, L. (2002). "FRP strengthened RC structures.”, John Wiley \& Sons, LTD, ISBN 0-471-48706-6. 
Ye, L. P., Lu X. Z., and Chen, J. F. (2005). "Design proposals for debonding strengths of FRP strengthened RC beams in the Chinese Design Code", Proceedings of International Symposium on Bond Behaviour of FRP in Structures , Hong Kong, China.

Zhang, Z., and Hsu, C-T. T. (2005). "Shear strengthening of reinforced concrete beams using carbon-fibrereinforced polymer laminates." J. Compos. Constr. 9(2), 158-169. 


\section{List of figures}

Fig. 1. Strengthening schemes for reinforced concrete beams

Fig. 2. Triantafillou (1998) and Triantafillou and Antonopoulos (2000) model comparison

Fig. 3. Khalifa et al. (1998) Khalifa and Nanni (2000) model comparison

Fig. 4. Chen and Teng (2003a, b) model comparison

Fig. 5. Deniaud and Cheng (2001 and 2004) model

Fig. 6. Adhikary et al. (2004) model comparison

Fig. 7. Ye et al. (2005) model comparison

Fig. 8. Cao et al. (2005) model comparison

Fig. 9. Zhang and Hsu model (2005) model comparison

Fig. 10. Carolin (2003) and Carolin and Täljsten (2005) model comparison

Fig. 11. Monti and Liota (2007) model comparison

\section{List of tables}

Table 1. Experimental database 
Fig. 12. Strengthening schemes for reinforced concrete beams

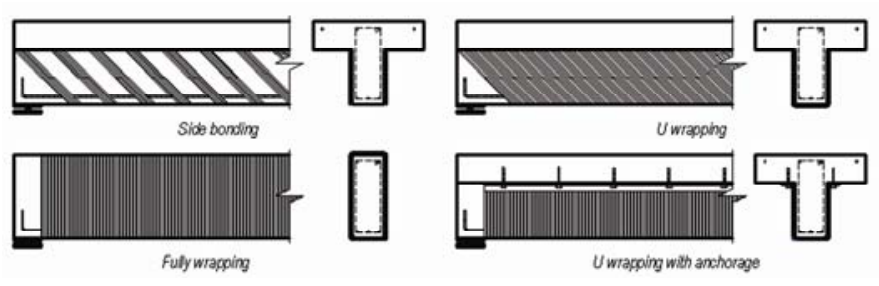

Fig. 13. Triantafillou (1998) and Triantafillou and Antonopoulos (2000) model comparison

Triantafillou (1998) and Triantafillou and Antonopoulos (2000)

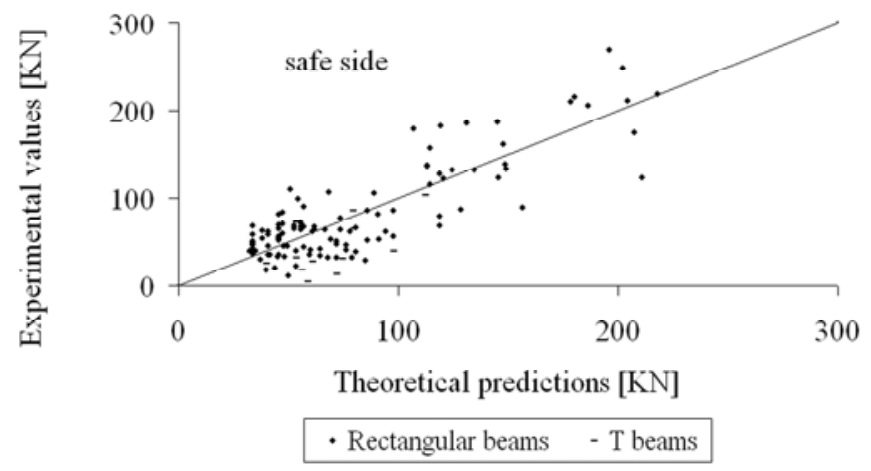

Fig. 14. Khalifa et al. (1998) Khalifa and Nanni (2000) model comparison

Khalifa et al. (1998) and Khalifa and Nanni (2000)

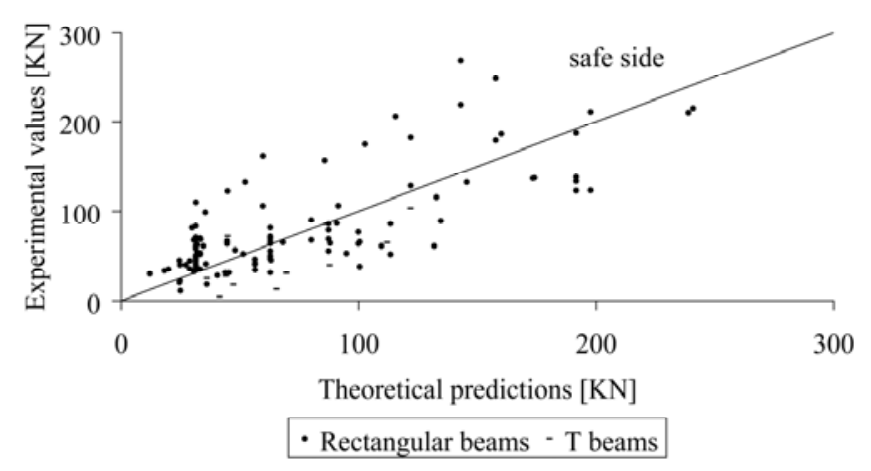

Fig. 15. Chen and Teng (2003a, b) model comparison 
Chen and Teng (2003a, b)

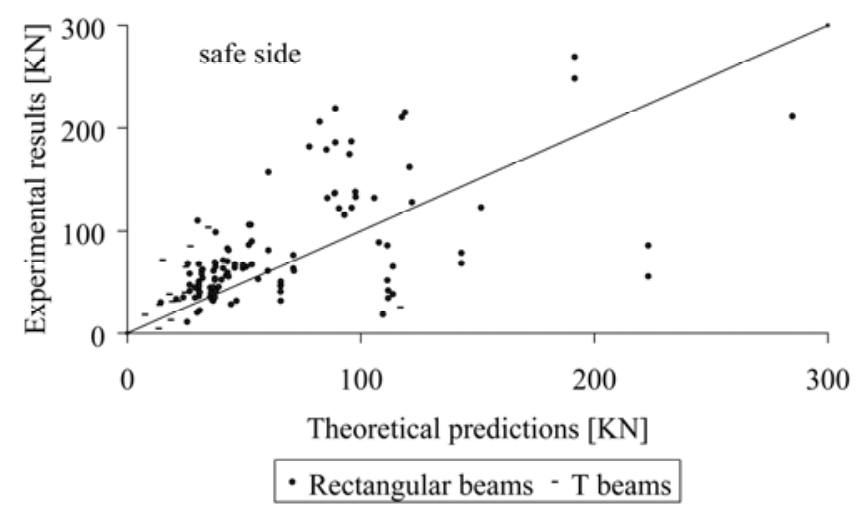

Fig. 16. Deniaud and Cheng (2001 and 2004) model

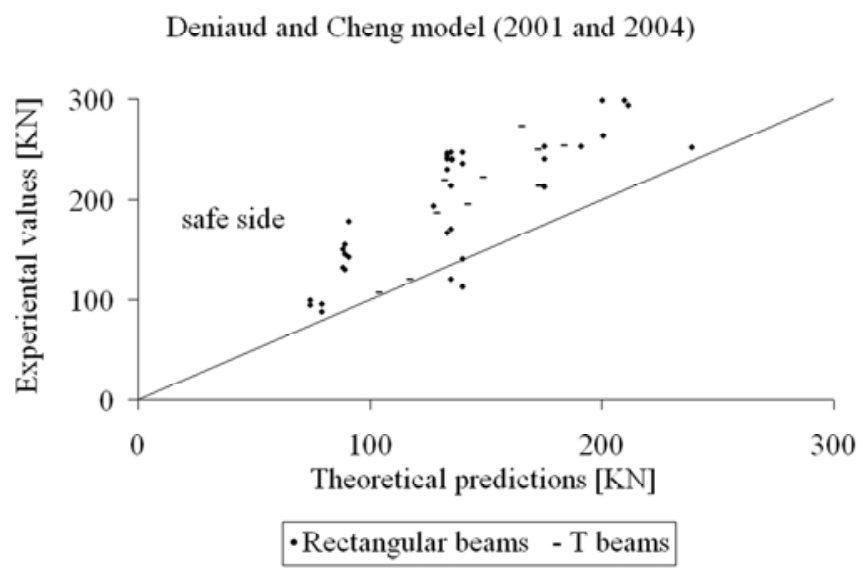

Fig. 17. Adhikary et al. (2004) model comparison

Adhikary et al. model (2004)

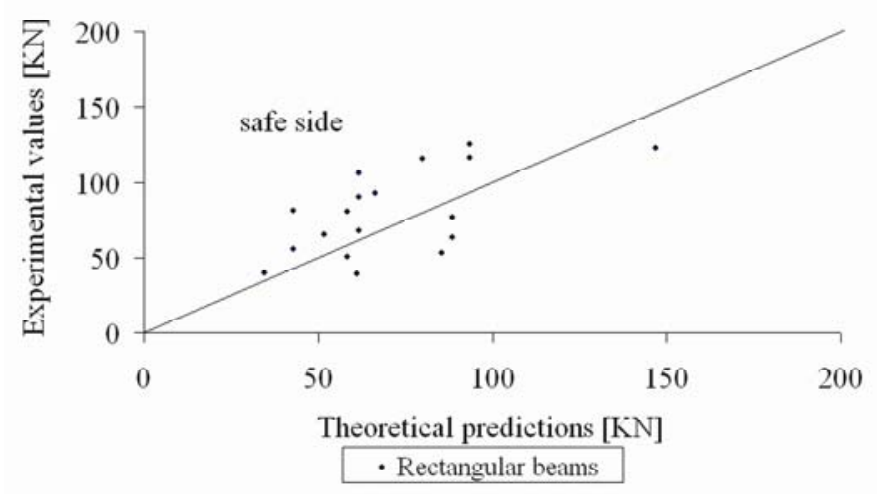


Fig. 18. Ye et al. (2005) model comparison

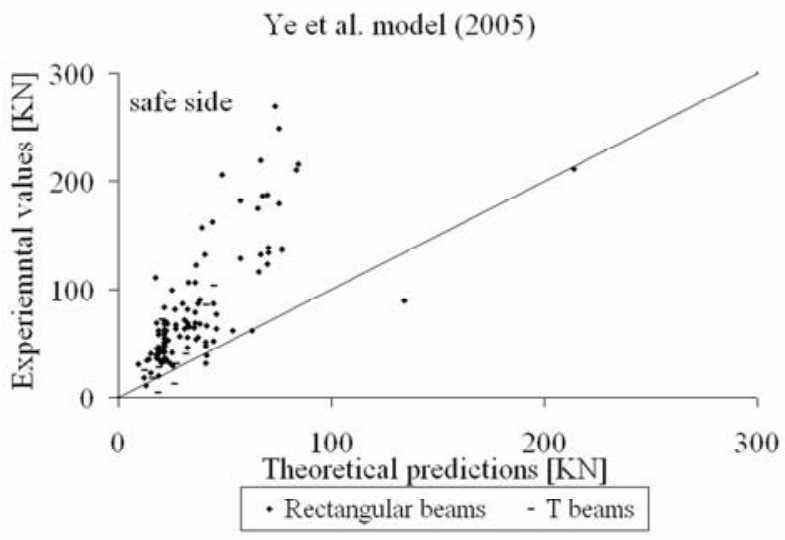

Fig. 19. Cao et al. (2005) model comparison

Cao et al. model (2005)

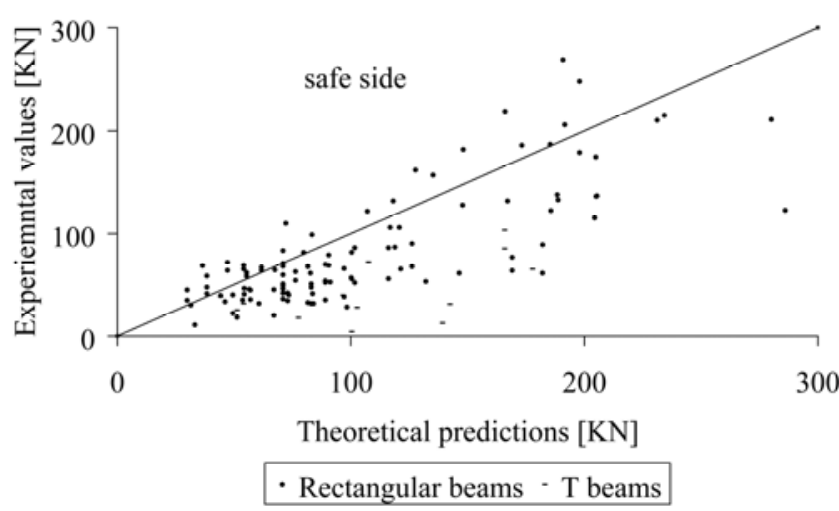

Fig. 20. Zhang and Hsu model (2005) model comparison 
Zhang and Hsu model (2005)

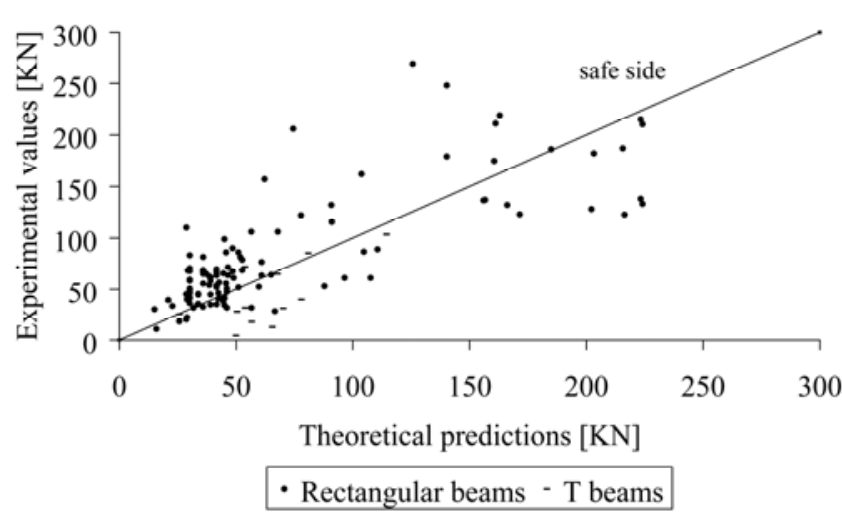

Fig. 21. Carolin (2003) and Carolin and Täljsten (2005) model comparison

Carolin (2003) and Carolin and Täljsten (2005)

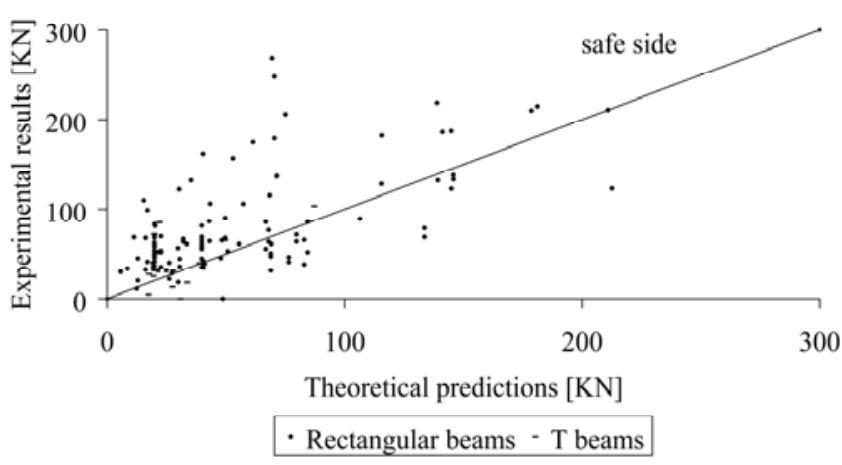

Fig. 22. Monti and Liota (2007) model comparison

Monti and Liotta model (2007)

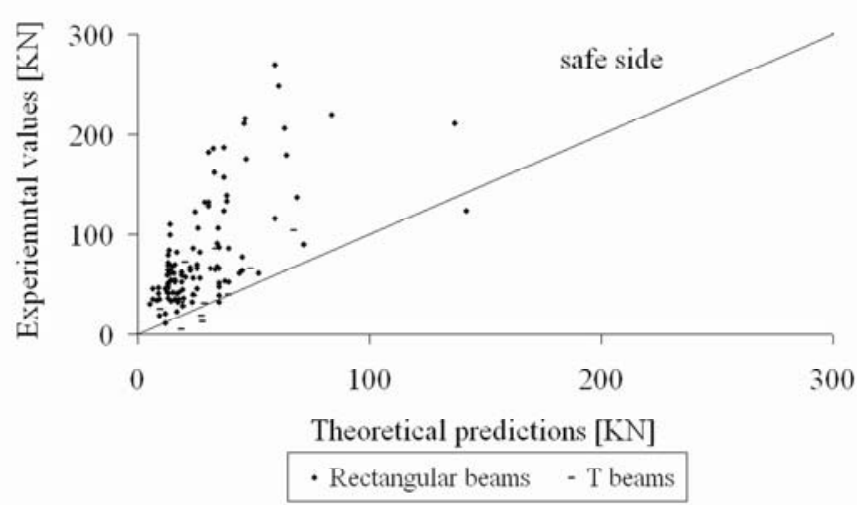


Tabel 1. Experimental database

Citation Reference

Original no.

Type $B_{\text {slab } T} \quad b_{\text {web }} \quad h \quad h_{\text {slab } T} \quad f_{c m} \quad f_{c k} \quad f_{\text {ctm }}$

$E_{c}$

Disc

Cont

Uji (1992)

Satto et al. (1996)

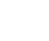

Araki et al. (1997)

\begin{tabular}{|c|c|c|c|c|c|c|c|c|c|c|c|c|c|c|c|c|c|c|c|}
\hline 3 & $\mathrm{R}$ & 0 & 100 & 200 & 0 & 32,60 & 24,60 & 2,54 & $3,136 \mathrm{E}+04$ & 230000 & 0,0115 & 2645 & W & $\mathrm{C}$ & 0,097 & 1 & 1 & 90 & 34,5 \\
\hline 5 & $\mathrm{R}$ & 0 & 100 & 200 & 0 & 32,60 & 24,60 & 2,54 & $3,136 \mathrm{E}+04$ & 230000 & 0,0115 & 2645 & $\mathrm{~S}$ & $\mathrm{C}$ & 0,097 & 1 & 1 & 90 & 20,5 \\
\hline 6 & $\mathrm{R}$ & 0 & 100 & 200 & 0 & 35,40 & 27,40 & 2,73 & $3,215 \mathrm{E}+04$ & 230000 & 0,0115 & 2645 & $\mathrm{~S}$ & $\mathrm{C}$ & 0,137 & 1 & 1,41 & 45 & 33 \\
\hline 7 & $\mathrm{R}$ & 0 & 100 & 200 & 0 & 35,40 & 27,40 & 2,73 & $3,215 \mathrm{E}+04$ & 230000 & 0,0115 & 2645 & $\mathrm{~S}$ & $\mathrm{C}$ & 0,195 & 1 & 1 & 90 & 20,5 \\
\hline $\mathrm{S} 2$ & $\mathrm{R}$ & 0 & 200 & 300 & 0 & 53,20 & 45,20 & 3,81 & $3,632 \mathrm{E}+04$ & 230000 & 0,0151 & 3473 & $\mathrm{~S}$ & $\mathrm{D}$ & 0,24 & 20 & 80 & 90 & 68,4 \\
\hline S3 & $\mathrm{R}$ & 0 & 200 & 300 & 0 & 49,30 & 41,30 & 3,58 & $3,550 \mathrm{E}+04$ & 230000 & 0,0151 & 3473 & $\mathrm{U}$ & $\mathrm{D}$ & 0,24 & 20 & 80 & 90 & 110 \\
\hline S4 & $\mathrm{R}$ & 0 & 200 & 300 & 0 & 45,50 & 37,50 & 3,36 & $3,466 \mathrm{E}+04$ & 230000 & 0,0151 & 3473 & $\mathrm{~S}$ & $\mathrm{C}$ & 0,12 & 1 & 1 & 90 & 64,2 \\
\hline S5 & $\mathrm{R}$ & 0 & 200 & 300 & 0 & 47,70 & 39,70 & 3,49 & $3,515 \mathrm{E}+04$ & 230000 & 0,0151 & 3473 & $\mathrm{U}$ & $\mathrm{C}$ & 0,12 & 1 & 1 & 90 & 106,1 \\
\hline CF045 & $\mathrm{R}$ & 0 & 200 & 400 & 0 & 32,80 & 24,80 & 2,55 & $3,142 \mathrm{E}+04$ & 230000 & 0,0151 & 3473 & W & $\mathrm{D}$ & 0,11 & 20 & 84,62 & 90 & 35 \\
\hline CF064 & $\mathrm{R}$ & 0 & 200 & 400 & 0 & 32,90 & 24,90 & 2,56 & $3,145 \mathrm{E}+04$ & 230000 & 0,0151 & 3473 & W & $\mathrm{D}$ & 0,11 & 20 & 48,89 & 90 & 61 \\
\hline CF097 & $\mathrm{R}$ & 0 & 200 & 400 & 0 & 33,20 & 25,20 & 2,58 & $3,153 \mathrm{E}+04$ & 230000 & 0,0151 & 3473 & W & $\mathrm{D}$ & 0,11 & 20 & 28,57 & 90 & 106 \\
\hline CF131 & $\mathrm{R}$ & 0 & 200 & 400 & 0 & 33,40 & 25,40 & 2,59 & $3,159 \mathrm{E}+04$ & 230000 & 0,0151 & 3473 & W & $\mathrm{C}$ & 0,11 & 1 & 1 & 90 & 157 \\
\hline & $\mathrm{R}$ & 0 & 200 & 400 & 0 & 33,60 & 25,60 & 2.61 & $3,165 E+04$ & 230000 & 0,0151 & 3473 & W & $\mathrm{C}$ & 0,22 & 1 & 1 & 90 & 206 \\
\hline
\end{tabular}




\begin{tabular}{|c|c|c|c|c|c|c|c|c|c|c|c|c|c|c|c|c|c|c|c|c|}
\hline \multirow[t]{3}{*}{ Funakawa et al. (1997) } & S2 & $\mathrm{R}$ & 0 & 600 & 600 & 0 & 38,00 & 30,00 & 2,90 & $3,284 \mathrm{E}+04$ & 240000 & 0,015833 & 3800 & $\mathrm{~W}$ & $\mathrm{C}$ & 0,167 & 1 & 1 & 90 & 242 \\
\hline & S3 & $\mathrm{R}$ & 0 & 600 & 600 & 0 & 38,00 & 30,00 & 2,90 & $3,284 \mathrm{E}+04$ & 240000 & 0,015833 & 3800 & W & $\mathrm{C}$ & 0,334 & 1 & 1 & 90 & 346 \\
\hline & S4 & $\mathrm{R}$ & 0 & 600 & 600 & 0 & 38,00 & 30,00 & 2,90 & $3,284 \mathrm{E}+04$ & 240000 & 0,015833 & 3800 & W & $\mathrm{C}$ & 0,501 & 1 & 1 & 90 & 493 \\
\hline \multirow[t]{3}{*}{ Miyauchi et al. (1997) } & $1 / 5 \mathrm{Z}-3$ & $\mathrm{R}$ & 0 & 125 & 200 & 0 & 43,10 & 35,10 & 3,22 & $3,410 \mathrm{E}+04$ & 230000 & 0,0151 & 3473 & W & $\mathrm{D}$ & 0,111 & 50 & 250 & 90 & 18,75 \\
\hline & $1 / 2 \mathrm{Z}-3$ & $\mathrm{R}$ & 0 & 125 & 200 & 0 & 40,40 & 32,40 & 3,05 & $3,345 \mathrm{E}+04$ & 230000 & 0,0151 & 3473 & W & $\mathrm{D}$ & 0,111 & 50 & 100 & 90 & 29,5 \\
\hline & 1/L Z-2 & $\mathrm{R}$ & 0 & 125 & 200 & 0 & 47,10 & 39,10 & 3,46 & $3,502 \mathrm{E}+04$ & 230000 & 0,0151 & 3473 & W & $\mathrm{D}$ & 0,111 & 50 & 100 & 90 & 34,55 \\
\hline \multirow[t]{2}{*}{ Kamiharako et al. (1997) } & 2 & $\mathrm{R}$ & 0 & 250 & 500 & 0 & 32,60 & 24,60 & 2,54 & $3,136 \mathrm{E}+04$ & 244000 & 0,016352 & 3990 & W & $\mathrm{D}$ & 0,11 & 40 & 100 & 90 & 28,1 \\
\hline & 7 & $\mathrm{R}$ & 0 & 400 & 700 & 0 & 34,60 & 26,60 & 2,67 & $3,193 \mathrm{E}+04$ & 244000 & 0,016352 & 3990 & $\mathrm{~W}$ & $\mathrm{D}$ & 0,11 & 64 & 100 & 90 & 174,7 \\
\hline \multirow[t]{5}{*}{ Taerwe et al. (1997) } & $\mathrm{BS} 2$ & $\mathrm{R}$ & 0 & 200 & 450 & 0 & 43,10 & 35,10 & 3,22 & $3,410 \mathrm{E}+04$ & 280000 & 0,0125 & 3500 & $\mathrm{U}$ & $\mathrm{D}$ & 0,11 & 100 & 400 & 90 & 41,2 \\
\hline & BS4 & $\mathrm{R}$ & 0 & 200 & 450 & 0 & 46,40 & 38,40 & 3,41 & $3,486 \mathrm{E}+04$ & 280000 & 0,0125 & 3500 & $\mathrm{U}$ & $\mathrm{C}$ & 0,11 & 1 & 1 & 90 & 115,4 \\
\hline & BS5 & $\mathrm{R}$ & 0 & 200 & 450 & 0 & 44,80 & 36,80 & 3,32 & $3,450 \mathrm{E}+04$ & 280000 & 0,0125 & 3500 & $\mathrm{U}$ & $\mathrm{D}$ & 0,11 & 50 & 400 & 90 & 33,4 \\
\hline & BS6 & $\mathrm{R}$ & 0 & 200 & 450 & 0 & 43,80 & 35,80 & 3,26 & $3,427 \mathrm{E}+04$ & 280000 & 0,0125 & 3500 & $\mathrm{U}$ & $\mathrm{D}$ & 0,11 & 50 & 600 & 90 & 30 \\
\hline & BS7 & $\mathrm{R}$ & 0 & 200 & 450 & 0 & 42,70 & 34,70 & 3,19 & $3,401 \mathrm{E}+04$ & 280000 & 0,0125 & 3500 & W & $\mathrm{D}$ & 0,11 & 50 & 200 & 90 & 98,9 \\
\hline \multirow[t]{3}{*}{ Umezu et al. (1997) } & $\mathrm{CS} 1$ & $\mathrm{R}$ & 0 & 300 & 300 & 0 & 48,50 & 40,50 & 3,54 & $3,533 \mathrm{E}+04$ & 244000 & 0,017213 & 4200 & W & $\mathrm{C}$ & 0,111 & 1 & 1 & 90 & 86,6 \\
\hline & $\mathrm{CS} 2$ & $\mathrm{R}$ & 0 & 300 & 300 & 0 & 48,50 & 40,50 & 3,54 & $3,533 \mathrm{E}+04$ & 244000 & 0,017213 & 4200 & W & $\mathrm{D}$ & 0,111 & 100 & 200 & 90 & 31,6 \\
\hline & $\mathrm{CS} 3$ & $\mathrm{R}$ & 0 & 150 & 300 & 0 & 52,80 & 44,80 & 3,78 & $3,624 \mathrm{E}+04$ & 244000 & 0,017213 & 4200 & W & $\mathrm{D}$ & 0,111 & 100 & 200 & 90 & 52,3 \\
\hline \multirow[t]{4}{*}{ Chaallal et al. (1998) } & RS90a & $\mathrm{R}$ & 0 & 150 & 250 & 0 & 35,00 & 27,00 & 2,70 & $3,204 \mathrm{E}+04$ & 150000 & 0,016 & 2400 & $\mathrm{~S}$ & $\mathrm{D}$ & 1 & 50 & 100 & 90 & 34,25 \\
\hline & RS90b & $\mathrm{R}$ & 0 & 150 & 250 & 0 & 35,00 & 27,00 & 2,70 & $3,204 \mathrm{E}+04$ & 150000 & 0,016 & 2400 & $\mathrm{~S}$ & $\mathrm{D}$ & 1 & 50 & 100 & 90 & 41,75 \\
\hline & RS135a & $\mathrm{R}$ & 0 & 150 & 250 & 0 & 35,00 & 27,00 & 2,70 & $3,204 \mathrm{E}+04$ & 150000 & 0,016 & 2400 & $\mathrm{~S}$ & $\mathrm{D}$ & 1 & 50 & 150 & 45 & 40,75 \\
\hline & RS135b & $\mathrm{R}$ & 0 & 150 & 250 & 0 & 35,00 & 27,00 & 2,70 & $3,204 \mathrm{E}+04$ & 150000 & 0,016 & 2400 & $\mathrm{~S}$ & $\mathrm{D}$ & 1 & 50 & 150 & 45 & 46,25 \\
\hline Mitsui et al. (1998) & A & $\mathrm{R}$ & 0 & 150 & 250 & 0 & 36,50 & 28,50 & 2,80 & $3,244 \mathrm{E}+04$ & 230000 & 0,015 & 3450 & $\mathrm{~W}+$ & $\mathrm{C}$ & 0,2775 & 1 & 1 & 90 & 40,2 \\
\hline
\end{tabular}


Triantafillou (1998)

\begin{tabular}{|c|c|c|c|c|c|c|c|c|c|c|c|c|c|c|c|c|c|c|c|}
\hline B & $\mathrm{R}$ & 0 & 150 & 250 & 0 & 36,50 & 28,50 & 2,80 & $3,244 \mathrm{E}+04$ & 230000 & 0,015 & 3450 & $\mathrm{~W}+$ & $\mathrm{C}$ & 0,2775 & 1 & 1 & 90 & 43,2 \\
\hline $\mathrm{C}$ & $\mathrm{R}$ & 0 & 150 & 250 & 0 & 36,50 & 28,50 & 2,80 & $3,244 \mathrm{E}+04$ & 230000 & 0,015 & 3450 & $\mathrm{~W}+$ & $\mathrm{C}$ & 0,2775 & 1 & 1 & 90 & 34,5 \\
\hline D & $\mathrm{R}$ & 0 & 150 & 250 & 0 & 36,50 & 28,50 & 2,80 & $3,244 \mathrm{E}+04$ & 230000 & 0,015 & 3450 & $\mathrm{~W}+$ & $\mathrm{C}$ & 0,2775 & 1 & 1 & 90 & 55,4 \\
\hline E & $\mathrm{R}$ & 0 & 150 & 250 & 0 & 36,50 & 28,50 & 2,80 & $3,244 \mathrm{E}+04$ & 230000 & 0,015 & 3450 & W+ & $\mathrm{C}$ & 0,2775 & 1 & 1 & 90 & 38 \\
\hline F & $\mathrm{R}$ & 0 & 150 & 250 & 0 & 36,50 & 28,50 & 2,80 & $3,244 \mathrm{E}+04$ & 230000 & 0,015 & 3450 & $\mathrm{~W}+$ & $\mathrm{C}$ & 0,2775 & 1 & 1 & 90 & 18 \\
\hline S1A & $\mathrm{R}$ & 0 & 70 & 110 & 0 & 30,00 & 22,00 & 2,36 & $3,059 \mathrm{E}+04$ & 235000 & 0,014043 & 3300 & S & $\mathrm{D}$ & 0,155 & 30 & 60 & 90 & 13,55 \\
\hline S1B & $\mathrm{R}$ & 0 & 70 & 110 & 0 & 30,00 & 22,00 & 2,36 & $3,059 \mathrm{E}+04$ & 235000 & 0,014043 & 3300 & $\mathrm{~S}$ & $\mathrm{D}$ & 0,155 & 30 & 60 & 90 & 11,25 \\
\hline S145 & $\mathrm{R}$ & 0 & 70 & 110 & 0 & 30,00 & 22,00 & 2,36 & $3,059 \mathrm{E}+04$ & 235000 & 0,014043 & 3300 & $\mathrm{~S}$ & $\mathrm{D}$ & 0,155 & 30 & 60 & 45 & 14,05 \\
\hline S2A & $\mathrm{R}$ & 0 & 70 & 110 & 0 & 30,00 & 22,00 & 2,36 & $3,059 \mathrm{E}+04$ & 235000 & 0,014043 & 3300 & $\mathrm{~S}$ & $\mathrm{D}$ & 0,155 & 45 & 60 & 90 & 15,85 \\
\hline S2B & $\mathrm{R}$ & 0 & 70 & 110 & 0 & 30,00 & 22,00 & 2,36 & $3,059 \mathrm{E}+04$ & 235000 & 0,014043 & 3300 & $\mathrm{~S}$ & D & 0,155 & 45 & 60 & 90 & 12,9 \\
\hline S245 & $\mathrm{R}$ & 0 & 70 & 110 & 0 & 30,00 & 22,00 & 2,36 & $3,059 \mathrm{E}+04$ & 235000 & 0,014043 & 3300 & $\mathrm{~S}$ & $\mathrm{D}$ & 0,155 & 30 & 60 & 45 & 15,45 \\
\hline S3A & $\mathrm{R}$ & 0 & 70 & 110 & 0 & 30,00 & 22,00 & 2,36 & $3,059 \mathrm{E}+04$ & 235000 & 0,014043 & 3300 & $\mathrm{~S}$ & $\mathrm{C}$ & 0,155 & 1 & 1 & 90 & 13,2 \\
\hline S3B & $\mathrm{R}$ & 0 & 70 & 110 & 0 & 30,00 & 22,00 & 2,36 & $3,059 \mathrm{E}+04$ & 235000 & 0,014043 & 3300 & $\mathrm{~S}$ & C & 0,155 & 1 & 1 & 90 & 10,55 \\
\hline S345 & $\mathrm{R}$ & 0 & 70 & 110 & 0 & 30,00 & 22,00 & 2,36 & $3,059 \mathrm{E}+04$ & 235000 & 0,014043 & 3300 & S & C & 0,155 & 1 & 1,4 & 45 & 12,15 \\
\hline CW2 & $\mathrm{R}$ & 0 & 150 & 305 & 0 & 35,50 & 27,50 & 2,73 & $3,217 \mathrm{E}+04$ & 228000 & 0,015351 & 3500 & $\mathrm{U}+$ & $\mathrm{C}$ & 0,165 & 1 & 1 & 90 & 39 \\
\hline $\mathrm{CO} 2$ & $\mathrm{R}$ & 0 & 150 & 305 & 0 & 28,50 & 20,50 & 2,25 & $3,012 \mathrm{E}+04$ & 228000 & 0,015351 & 3500 & $\mathrm{U}$ & $\mathrm{D}$ & 0,165 & 50 & 125 & 90 & 40 \\
\hline $\mathrm{CO} 3$ & $\mathrm{R}$ & 0 & 150 & 305 & 0 & 28,50 & 20,50 & 2,25 & $3,012 \mathrm{E}+04$ & 228000 & 0,015351 & 3500 & $\mathrm{U}$ & $\mathrm{C}$ & 0,165 & 1 & 1 & 90 & 65 \\
\hline BT2 & $\mathrm{T}$ & 380 & 150 & 405 & 100 & 35,00 & 27,00 & 2,70 & $3,204 \mathrm{E}+04$ & 228000 & 0,016623 & 3790 & $\mathrm{U}$ & $\mathrm{C}$ & 0,165 & 1 & 1 & 90 & 65,0 \\
\hline BT3 & $\mathrm{T}$ & 380 & 150 & 405 & 100 & 35,00 & 27,00 & 2,70 & $3,204 \mathrm{E}+04$ & 228000 & 0,016623 & 3790 & U+ & $\mathrm{C}$ & 0,165 & 1 & 1 & 90 & 67,5 \\
\hline BT4 & $\mathrm{T}$ & 380 & 150 & 405 & 100 & 35,00 & 27,00 & 2,70 & $3,204 \mathrm{E}+04$ & 228000 & 0,016623 & 3790 & U & $\mathrm{D}$ & 0,165 & 50 & 125 & 90 & 72,0 \\
\hline BT5 & $\mathrm{T}$ & 380 & 150 & 405 & 100 & 35,00 & 27,00 & 2,70 & $3,204 \mathrm{E}+04$ & 228000 & 0,016623 & 3790 & $\mathrm{~S}$ & D & 0,165 & 50 & 125 & 90 & 31,5 \\
\hline
\end{tabular}




\begin{tabular}{|c|c|c|c|c|c|c|c|c|c|c|c|c|c|c|c|c|c|c|c|c|}
\hline & BT6 & $\mathrm{T}$ & 380 & 150 & 405 & 100 & 35,00 & 27,00 & 2,70 & $3,204 \mathrm{E}+04$ & 228000 & 0,016623 & 3790 & $\mathrm{U}+$ & $\mathrm{C}$ & 0,165 & 1 & 1 & 90 & 131,0 \\
\hline \multirow[t]{3}{*}{ Täljsten and Elfgren (2000) } & S4 & $\mathrm{R}$ & 0 & 180 & 500 & 0 & 56,50 & 48,50 & 3,99 & $3,699 \mathrm{E}+04$ & 70800 & 0,012147 & 860 & $\mathrm{U}$ & $\mathrm{C}$ & 0,8 & 1 & 1,41 & 45 & 211 \\
\hline & SR1 & $\mathrm{R}$ & 0 & 180 & 500 & 0 & 61,80 & 53,80 & 4,28 & $3,799 \mathrm{E}+04$ & 70800 & 0,012147 & 860 & $\mathrm{U}$ & $\mathrm{D}$ & 0,8 & 50 & 141,42 & 45 & 89 \\
\hline & SR2 & $\mathrm{R}$ & 0 & 180 & 500 & 0 & 60,70 & 52,70 & 4,22 & $3,779 \mathrm{E}+04$ & 70800 & 0,012147 & 860 & $\mathrm{U}$ & $\mathrm{C}$ & 0,8 & 1 & 1,41 & 45 & 123 \\
\hline \multirow[t]{3}{*}{ Deniaud and Cheng (2001) } & T6NS-C45 & $\mathrm{T}$ & 400 & 140 & 600 & 150 & 44,10 & 36,10 & 3,28 & $3,434 \mathrm{E}+04$ & 230000 & 0,014783 & 3400 & $\mathrm{U}$ & $\mathrm{D}$ & 0,11 & 50 & 100 & 45 & 103,5 \\
\hline & T6S4-C90 & $\mathrm{T}$ & 400 & 140 & 600 & 150 & 44,10 & 36,10 & 3,28 & $3,434 \mathrm{E}+04$ & 230000 & 0,014783 & 3400 & $\mathrm{U}$ & $\mathrm{D}$ & 0,11 & 50 & 100 & 90 & 85,25 \\
\hline & T6S2-C90 & $\mathrm{T}$ & 400 & 140 & 600 & 150 & 44,10 & 36,10 & 3,28 & $3,434 \mathrm{E}+04$ & 230000 & 0,014783 & 3400 & $\mathrm{U}$ & $\mathrm{D}$ & 0,11 & 50 & 100 & 90 & 0 \\
\hline \multirow[t]{4}{*}{ Park et al. (2001) } & 2 & $\mathrm{R}$ & 0 & 100 & 250 & 0 & 33,40 & 25,40 & 2,59 & 31589,78 & 240000 & 0,014167 & 3400 & $\mathrm{U}$ & $\mathrm{C}$ & 0,16 & 1 & 1 & 90 & 39,3 \\
\hline & 3 & $\mathrm{R}$ & 0 & 100 & 250 & 0 & 33,4 & 25,40 & 2,59 & 31589,78 & 155000 & 0,015484 & 2400 & $\mathrm{~S}$ & $\mathrm{D}$ & 1,2 & 25 & 75 & 90 & 18,1 \\
\hline & 5 & $\mathrm{~T}$ & 300 & 100 & 300 & 50 & 33,4 & 25,40 & 2,59 & 31589,78 & 240000 & 0,014167 & 3400 & $\mathrm{U}$ & $\mathrm{C}$ & 0,16 & 1 & 1 & 90 & 38,1 \\
\hline & 6 & $\mathrm{~T}$ & 300 & 100 & 300 & 50 & 33,4 & 25,40 & 2,59 & 31589,78 & 155000 & 0,015484 & 2400 & $\mathrm{~S}$ & $\mathrm{D}$ & 1,2 & 25 & 75 & 90 & 25,1 \\
\hline \multirow[t]{10}{*}{ Li et al. (2002) } & B80_1 & $\mathrm{R}$ & 0 & 130 & 300 & 0 & 38,00 & 30,00 & 2,90 & $3,284 \mathrm{E}+04$ & 42400 & 0,011085 & 470 & $\mathrm{~S}+$ & $\mathrm{C}$ & 1,5 & 1 & 1,41 & 45 & 12 \\
\hline & B80_2 & $\mathrm{R}$ & 0 & 130 & 300 & 0 & 38,00 & 30,00 & 2,90 & $3,284 \mathrm{E}+04$ & 42400 & 0,011085 & 470 & $\mathrm{~S}+$ & $\mathrm{C}$ & 1,5 & 1 & 1,41 & 45 & 23,5 \\
\hline & B80_3 & $\mathrm{R}$ & 0 & 130 & 300 & 0 & 38,00 & 30,00 & 2,90 & $3,284 \mathrm{E}+04$ & 42400 & 0,011085 & 470 & $\mathrm{~S}+$ & $\mathrm{C}$ & 1,5 & 1 & 1,41 & 45 & 22 \\
\hline & B40_1 & $\mathrm{R}$ & 0 & 130 & 300 & 0 & 38,00 & 30,00 & 2,90 & $3,284 \mathrm{E}+04$ & 42400 & 0,011085 & 470 & $\mathrm{~S}+$ & $\mathrm{C}$ & 1,5 & 1 & 1,41 & 45 & 10,5 \\
\hline & B20_1 & $\mathrm{R}$ & 0 & 130 & 300 & 0 & 38,00 & 30,00 & 2,90 & $3,284 \mathrm{E}+04$ & 42400 & 0,011085 & 470 & $\mathrm{~S}+$ & $\mathrm{C}$ & 1,5 & 1 & 1,41 & 45 & 7,5 \\
\hline & B20_2 & $\mathrm{R}$ & 0 & 130 & 300 & 0 & 38,00 & 30,00 & 2,90 & $3,284 \mathrm{E}+04$ & 42400 & 0,011085 & 470 & $\mathrm{~S}+$ & $\mathrm{C}$ & 1,5 & 1 & 1,41 & 45 & 13,5 \\
\hline & B20_3 & $\mathrm{R}$ & 0 & 130 & 300 & 0 & 38,00 & 30,00 & 2,90 & $3,284 \mathrm{E}+04$ & 42400 & 0,011085 & 470 & $\mathrm{~S}+$ & $\mathrm{C}$ & 1,5 & 1 & 1,41 & 45 & 13 \\
\hline & B10_1 & $\mathrm{R}$ & 0 & 130 & 300 & 0 & 38,00 & 30,00 & 2,90 & $3,284 \mathrm{E}+04$ & 42400 & 0,011085 & 470 & $\mathrm{~S}+$ & $\mathrm{C}$ & 1,5 & 1 & 1,41 & 45 & 0 \\
\hline & B'80_2 & $\mathrm{R}$ & 0 & 130 & 300 & 0 & 38,00 & 30,00 & 2,90 & $3,284 \mathrm{E}+04$ & 42400 & 0,011085 & 470 & $\mathrm{~S}+$ & $\mathrm{C}$ & 1,5 & 1 & 1,41 & 45 & 20,5 \\
\hline & B'20_2 & $\mathrm{R}$ & 0 & 130 & 300 & 0 & 38,00 & 30,00 & 2,90 & $3,284 \mathrm{E}+04$ & 42400 & 0,011085 & 470 & $\mathrm{~S}+$ & $\mathrm{C}$ & 1,5 & 1 & 1,41 & 45 & 30,5 \\
\hline
\end{tabular}




\begin{tabular}{|c|c|c|c|c|c|c|c|c|c|c|c|c|c|c|c|c|c|c|c|}
\hline TR30D10 & $\mathrm{R}$ & 0 & 150 & 300 & 0 & 31,40 & 23,40 & 2,45 & $3,101 \mathrm{E}+04$ & 234000 & 0,015171 & 3550 & $\mathrm{~S}$ & $\mathrm{C}$ & 0,33 & 1 & 1 & 90 & 31,5 \\
\hline TR30D2 & $\mathrm{R}$ & 0 & 150 & 300 & 0 & 31,40 & 23,40 & 2,45 & $3,101 \mathrm{E}+04$ & 234000 & 0,015171 & 3550 & $\mathrm{~S}$ & $\mathrm{C}$ & 0,495 & 1 & 1 & 90 & 51,8 \\
\hline TR30D20 & $\mathrm{R}$ & 0 & 150 & 300 & 0 & 31,40 & 23,40 & 2,45 & $3,101 \mathrm{E}+04$ & 234000 & 0,015171 & 3550 & $\mathrm{~S}$ & $\mathrm{C}$ & 0,495 & 1 & 1 & 90 & 86 \\
\hline TR30D3 & $\mathrm{R}$ & 0 & 150 & 300 & 0 & 31,40 & 23,40 & 2,45 & $3,101 \mathrm{E}+04$ & 234000 & 0,015171 & 3550 & $\mathrm{~S}$ & $\mathrm{C}$ & 0,165 & 1 & 1 & 90 & 0 \\
\hline TR30D4 & $\mathrm{R}$ & 0 & 150 & 300 & 0 & 31,40 & 23,40 & 2,45 & $3,101 \mathrm{E}+04$ & 234000 & 0,015171 & 3550 & S & $\mathrm{C}$ & 0,33 & 1 & 1 & 90 & 47,3 \\
\hline TR30D40 & $\mathrm{R}$ & 0 & 150 & 300 & 0 & 31,40 & 23,40 & 2,45 & $3,101 \mathrm{E}+04$ & 234000 & 0,015171 & 3550 & $\mathrm{~S}$ & $\mathrm{C}$ & 0,33 & 1 & 1 & 90 & 50,5 \\
\hline V9_A & $\mathrm{R}$ & 0 & 150 & 300 & 0 & 32,80 & 24,80 & 2,55 & $3,142 \mathrm{E}+04$ & 230000 & 0,014783 & 3400 & $\mathrm{~S}$ & $\mathrm{D}$ & 0,111 & 50 & 100 & 90 & 41,2 \\
\hline V9_B & $\mathrm{R}$ & 0 & 150 & 300 & 0 & 32,80 & 24,80 & 2,55 & $3,142 \mathrm{E}+04$ & 230000 & 0,014783 & 3400 & $\mathrm{~S}$ & D & 0,111 & 50 & 100 & 90 & 47,37 \\
\hline V21_A & $\mathrm{R}$ & 0 & 150 & 300 & 0 & 32,80 & 24,80 & 2,55 & $3,142 \mathrm{E}+04$ & 230000 & 0,014783 & 3400 & $\mathrm{~S}$ & $\mathrm{D}$ & 0,111 & 50 & 100 & 90 & 58,27 \\
\hline V10_A & $\mathrm{R}$ & 0 & 150 & 300 & 0 & 32,80 & 24,80 & 2,55 & $3,142 \mathrm{E}+04$ & 230000 & 0,014783 & 3400 & U & $\mathrm{D}$ & 0,111 & 50 & 100 & 90 & 50,57 \\
\hline V10_B & $\mathrm{R}$ & 0 & 150 & 300 & 0 & 32,80 & 24,80 & 2,55 & $3,142 \mathrm{E}+04$ & 230000 & 0,014783 & 3400 & U & $\mathrm{D}$ & 0,111 & 50 & 100 & 90 & 49,07 \\
\hline V17_A & $\mathrm{R}$ & 0 & 150 & 300 & 0 & 32,80 & 24,80 & 2,55 & $3,142 \mathrm{E}+04$ & 230000 & 0,014783 & 3400 & U & $\mathrm{D}$ & 0,111 & 50 & 100 & 90 & 45,87 \\
\hline V11_A & $\mathrm{R}$ & 0 & 150 & 300 & 0 & 32,80 & 24,80 & 2,55 & $3,142 \mathrm{E}+04$ & 230000 & 0,014783 & 3400 & $\mathrm{U}$ & D & 0,111 & 50 & 100 & 90 & 41,51 \\
\hline V11_B & $\mathrm{R}$ & 0 & 150 & 300 & 0 & 32,80 & 24,80 & 2,55 & $3,142 \mathrm{E}+04$ & 230000 & 0,014783 & 3400 & $\mathrm{U}$ & $\mathrm{D}$ & 0,111 & 50 & 100 & 90 & 67,88 \\
\hline V17_B & $\mathrm{R}$ & 0 & 150 & 300 & 0 & 32,80 & 24,80 & 2,55 & $3,142 \mathrm{E}+04$ & 230000 & 0,014783 & 3400 & $\mathrm{U}$ & D & 0,111 & 50 & 100 & 90 & 36,01 \\
\hline V12_A & $\mathrm{R}$ & 0 & 150 & 300 & 0 & 32,80 & 24,80 & 2,55 & $3,142 \mathrm{E}+04$ & 230000 & 0,014783 & 3400 & W & D & 0,111 & 50 & 100 & 90 & 59,44 \\
\hline V18_A & $\mathrm{R}$ & 0 & 150 & 300 & 0 & 32,80 & 24,80 & 2,55 & $3,142 \mathrm{E}+04$ & 230000 & 0,014783 & 3400 & W & $\mathrm{D}$ & 0,111 & 50 & 100 & 90 & 70,37 \\
\hline V20_A & $\mathrm{R}$ & 0 & 150 & 300 & 0 & 32,80 & 24,80 & 2,55 & $3,142 \mathrm{E}+04$ & 230000 & 0,014783 & 3400 & W & D & 0,111 & 50 & 100 & 90 & 83,2 \\
\hline V12_B & $\mathrm{R}$ & 0 & 150 & 300 & 0 & 32,80 & 24,80 & 2,55 & $3,142 \mathrm{E}+04$ & 230000 & 0,014783 & 3400 & $\mathrm{~S}$ & D & 0,111 & 50 & 141,4 & 45 & 44,73 \\
\hline V14_B & $\mathrm{R}$ & 0 & 150 & 300 & 0 & 32,80 & 24,80 & 2,55 & $3,142 \mathrm{E}+04$ & 230000 & 0,014783 & 3400 & $\mathrm{~S}$ & D & 0,111 & 50 & 141,4 & 45 & 34,73 \\
\hline V19_A & $\mathrm{R}$ & 0 & 150 & 300 & 0 & 32,80 & 24,80 & 2,55 & $3,142 \mathrm{E}+04$ & 230000 & 0,014783 & 3400 & U & D & 0,111 & 50 & 141,4 & 45 & 61,5 \\
\hline
\end{tabular}




\begin{tabular}{|c|c|c|c|c|c|c|c|c|c|c|c|c|c|c|c|c|c|c|c|c|}
\hline & V19_B & $\mathrm{R}$ & 0 & 150 & 300 & 0 & 32,80 & 24,80 & 2,55 & $3,142 \mathrm{E}+04$ & 230000 & 0,014783 & 3400 & $\mathrm{U}$ & $\mathrm{D}$ & 0,111 & 50 & 141,4 & 45 & 58,21 \\
\hline & V13_A & $\mathrm{R}$ & 0 & 150 & 300 & 0 & 32,80 & 24,80 & 2,55 & $3,142 \mathrm{E}+04$ & 230000 & 0,014783 & 3400 & $\mathrm{~S}$ & $\mathrm{C}$ & 0,111 & 1 & 1 & 90 & 65,09 \\
\hline & V13_B & $\mathrm{R}$ & 0 & 150 & 300 & 0 & 32,80 & 24,80 & 2,55 & $3,142 \mathrm{E}+04$ & 230000 & 0,014783 & 3400 & $\mathrm{~S}$ & $\mathrm{C}$ & 0,111 & 1 & 1 & 90 & 68,83 \\
\hline & V15_B & $\mathrm{R}$ & 0 & 150 & 300 & 0 & 32,80 & 24,80 & 2,55 & $3,142 \mathrm{E}+04$ & 230000 & 0,014783 & 3400 & $\mathrm{U}$ & $\mathrm{C}$ & 0,111 & 1 & 1 & 90 & 81,45 \\
\hline & V16_B & $\mathrm{R}$ & 0 & 150 & 300 & 0 & 32,80 & 24,80 & 2,55 & $3,142 \mathrm{E}+04$ & 230000 & 0,014783 & 3400 & $\mathrm{U}$ & $\mathrm{C}$ & 0,111 & 1 & 1 & 90 & 55,51 \\
\hline & V14_A & $\mathrm{R}$ & 0 & 150 & 300 & 0 & 32,80 & 24,80 & 2,55 & $3,142 \mathrm{E}+04$ & 230000 & 0,014783 & 3400 & $\mathrm{~S}$ & $\mathrm{C}$ & 0,111 & 1 & 1,41 & 45 & 71,47 \\
\hline & V15_A & $\mathrm{R}$ & 0 & 150 & 300 & 0 & 32,80 & 24,80 & 2,55 & $3,142 \mathrm{E}+04$ & 230000 & 0,014783 & 3400 & $\mathrm{~S}$ & $\mathrm{C}$ & 0,111 & 1 & 1,41 & 45 & 63,64 \\
\hline & V20_B & $\mathrm{R}$ & 0 & 150 & 300 & 0 & 32,80 & 24,80 & 2,55 & $3,142 \mathrm{E}+04$ & 205000 & 0,012195 & 2500 & $\mathrm{~S}$ & $\mathrm{D}$ & 1,4 & 50 & 100 & 90 & 85,99 \\
\hline & V22_B & $\mathrm{R}$ & 0 & 150 & 300 & 0 & 32,80 & 24,80 & 2,55 & $3,142 \mathrm{E}+04$ & 205000 & 0,012195 & 2500 & $\mathrm{~S}$ & $\mathrm{D}$ & 1,4 & 50 & 100 & 90 & 55,59 \\
\hline & V21_B & $\mathrm{R}$ & 0 & 150 & 300 & 0 & 32,80 & 24,80 & 2,55 & $3,142 \mathrm{E}+04$ & 205000 & 0,012195 & 2500 & $\mathrm{~S}$ & $\mathrm{D}$ & 1,4 & 50 & 141,4 & 45 & 78,78 \\
\hline & V22_A & $\mathrm{R}$ & 0 & 150 & 300 & 0 & 32,80 & 24,80 & 2,55 & $3,142 \mathrm{E}+04$ & 205000 & 0,012195 & 2500 & $\mathrm{~S}$ & $\mathrm{D}$ & 1,4 & 50 & 141,4 & 45 & 68,68 \\
\hline Deniaud and Cheng (2003) & $\mathrm{T} 4 \mathrm{~S} 2-\mathrm{C} 45$ & $\mathrm{~T}$ & 400 & 140 & 400 & 150 & 37,40 & 29,40 & 2,86 & $3,268 \mathrm{E}+04$ & 230000 & 0,014783 & 3400 & $\mathrm{U}$ & $\mathrm{D}$ & 0,11 & 50 & 141 & 45 & 17,8 \\
\hline \multirow[t]{8}{*}{ Diagana et al. (2003) } & PU1 & $\mathrm{R}$ & 0 & 130 & 450 & 0 & 38,00 & 30,00 & 2,90 & $3,284 \mathrm{E}+04$ & 105000 & 0,013333 & 1400 & $\mathrm{U}$ & $\mathrm{D}$ & 0,43 & 40 & 200 & 90 & 32,5 \\
\hline & PU2 & $\mathrm{R}$ & 0 & 130 & 450 & 0 & 38,00 & 30,00 & 2,90 & $3,284 \mathrm{E}+04$ & 105000 & 0,013333 & 1400 & $\mathrm{U}$ & $\mathrm{D}$ & 0,43 & 40 & 250 & 90 & 20 \\
\hline & PU3 & $\mathrm{R}$ & 0 & 130 & 450 & 0 & 38,00 & 30,00 & 2,90 & $3,284 \mathrm{E}+04$ & 105000 & 0,013333 & 1400 & $\mathrm{U}$ & $\mathrm{D}$ & 0,43 & 40 & 300 & 45 & 44,5 \\
\hline & PU4 & $\mathrm{R}$ & 0 & 130 & 450 & 0 & 38,00 & 30,00 & 2,90 & $3,284 \mathrm{E}+04$ & 105000 & 0,013333 & 1400 & $\mathrm{U}$ & $\mathrm{D}$ & 0,43 & 40 & 350 & 45 & 40 \\
\hline & $\mathrm{PC} 1$ & $\mathrm{R}$ & 0 & 130 & 450 & 0 & 38,00 & 30,00 & 2,90 & $3,284 \mathrm{E}+04$ & 105000 & 0,013333 & 1400 & W & $\mathrm{D}$ & 0,43 & 40 & 200 & 90 & 67,5 \\
\hline & PC2 & $\mathrm{R}$ & 0 & 130 & 450 & 0 & 38,00 & 30,00 & 2,90 & $3,284 \mathrm{E}+04$ & 105000 & 0,013333 & 1400 & W & $\mathrm{D}$ & 0,43 & 40 & 250 & 90 & 45 \\
\hline & PC3 & $\mathrm{R}$ & 0 & 130 & 450 & 0 & 38,00 & 30,00 & 2,90 & $3,284 \mathrm{E}+04$ & 105000 & 0,013333 & 1400 & W & $\mathrm{D}$ & 0,43 & 40 & 300 & 45 & 35,5 \\
\hline & PC4 & $\mathrm{R}$ & 0 & 130 & 450 & 0 & 38,00 & 30,00 & 2,90 & $3,284 \mathrm{E}+04$ & 105000 & 0,013333 & 1400 & W & $\mathrm{D}$ & 0,43 & 40 & 350 & 45 & 22 \\
\hline Täljsten (2003) & $\mathrm{RC} 1$ & $\mathrm{R}$ & 0 & 180 & 500 & 0 & 67,40 & 59,40 & 4,57 & $3,900 \mathrm{E}+04$ & 234000 & 0,019231 & 4500 & $\mathrm{~S}$ & C & 0,07 & 1 & 1,41 & 45 & 182 \\
\hline
\end{tabular}


Adhikary et al. (2004)

Feng Xue Song et al. (2004)

Carolin and Täljsten (2005)

\begin{tabular}{|c|c|c|c|c|c|c|c|c|c|c|c|c|c|c|c|c|c|c|c|}
\hline $\mathrm{C} 1$ & $\mathrm{R}$ & 0 & 180 & 500 & 0 & 67,40 & 59,40 & 4,57 & $3,900 \mathrm{E}+04$ & 234000 & 0,019231 & 4500 & $\mathrm{~S}$ & $\mathrm{C}$ & 0,11 & 1 & 1,41 & 45 & 122,6 \\
\hline $\mathrm{C} 2$ & $\mathrm{R}$ & 0 & 180 & 500 & 0 & 71,40 & 63,40 & 4,77 & $3,968 \mathrm{E}+04$ & 234000 & 0,019231 & 4500 & $\mathrm{~S}$ & $\mathrm{C}$ & 0,11 & 1 & 1,41 & 45 & 133,15 \\
\hline $\mathrm{C} 3$ & $\mathrm{R}$ & 0 & 180 & 500 & 0 & 58,70 & 50,70 & 4,11 & $3,741 \mathrm{E}+04$ & 234000 & 0,019231 & 4500 & $\mathrm{~S}$ & $\mathrm{C}$ & 0,11 & 1 & 1 & 90 & 136,55 \\
\hline $\mathrm{C} 5$ & $\mathrm{R}$ & 0 & 180 & 500 & 0 & 71,40 & 63,40 & 4,77 & $3,968 \mathrm{E}+04$ & 234000 & 0,019231 & 4500 & $\mathrm{~S}$ & $\mathrm{C}$ & 0,165 & 1 & 1,41 & 45 & 210,25 \\
\hline $\mathrm{C} 1$ & $\mathrm{R}$ & 0 & 300 & 300 & 0 & 45,20 & 37,20 & 3,34 & $3,459 \mathrm{E}+04$ & 230000 & 0,014783 & 3400 & $\mathrm{U}$ & $\mathrm{C}$ & 0,167 & 1 & 1 & 90 & 53 \\
\hline $\mathrm{C} 2$ & $\mathrm{R}$ & 0 & 300 & 300 & 0 & 49,10 & 41,10 & 3,57 & $3,546 \mathrm{E}+04$ & 230000 & 0,014783 & 3400 & U+ & $\mathrm{C}$ & 0,167 & 1 & 1 & 90 & 116,5 \\
\hline $\mathrm{C} 3$ & $\mathrm{R}$ & 0 & 300 & 300 & 0 & 49,10 & 41,10 & 3,57 & $3,546 \mathrm{E}+04$ & 230000 & 0,014783 & 3400 & U+ & $\mathrm{C}$ & 0,167 & 1 & 1 & 90 & 125,5 \\
\hline SB1_3 & $\mathrm{R}$ & 0 & 150 & 360 & 0 & 32,50 & 24,50 & 2,53 & $3,133 \mathrm{E}+04$ & 235000 & 0,017872 & 4200 & $\mathrm{U}$ & $\mathrm{C}$ & 0,22 & 1 & 1 & 90 & 63,5 \\
\hline SB1_4 & $\mathrm{R}$ & 0 & 150 & 360 & 0 & 32,50 & 24,50 & 2,53 & $3,133 \mathrm{E}+04$ & 235000 & 0,017872 & 4200 & $\mathrm{U}$ & $\mathrm{C}$ & 0,22 & 1 & 1 & 90 & 76,5 \\
\hline SB1_5 & $\mathrm{R}$ & 0 & 150 & 360 & 0 & 32,50 & 24,50 & 2,53 & $3,133 \mathrm{E}+04$ & 235000 & 0,017872 & 4200 & $\mathrm{U}$ & D & 0,22 & 40 & 120 & 90 & 69,5 \\
\hline SB1_6 & $\mathrm{R}$ & 0 & 150 & 360 & 0 & 32,50 & 24,50 & 2,53 & $3,133 \mathrm{E}+04$ & 235000 & 0,017872 & 4200 & $\mathrm{U}$ & $\mathrm{D}$ & 0,22 & 40 & 120 & 90 & 53,5 \\
\hline SB1_7 & $\mathrm{R}$ & 0 & 150 & 360 & 0 & 32,50 & 24,50 & 2,53 & $3,133 \mathrm{E}+04$ & 235000 & 0,017872 & 4200 & U+ & D & 0,22 & 40 & 120 & 90 & 63,5 \\
\hline SB1_8 & $\mathrm{R}$ & 0 & 150 & 360 & 0 & 32,50 & 24,50 & 2,53 & $3,133 \mathrm{E}+04$ & 235000 & 0,017872 & 4200 & U+ & $\mathrm{D}$ & 0,22 & 40 & 120 & 90 & 62,5 \\
\hline SB1_9 & $\mathrm{R}$ & 0 & 150 & 360 & 0 & 32,50 & 24,50 & 2,53 & $3,133 \mathrm{E}+04$ & 235000 & 0,017872 & 4200 & $\mathrm{U}$ & $\mathrm{D}$ & 0,44 & 40 & 120 & 90 & 63,5 \\
\hline SB1_10 & $\mathrm{R}$ & 0 & 150 & 360 & 0 & 32,50 & 24,50 & 2,53 & $3,133 \mathrm{E}+04$ & 235000 & 0,017872 & 4200 & $\mathrm{U}$ & $\mathrm{D}$ & 0,44 & 40 & 120 & 90 & 66,5 \\
\hline SB2_2 & $\mathrm{R}$ & 0 & 150 & 360 & 0 & 32,50 & 24,50 & 2,53 & $3,133 \mathrm{E}+04$ & 235000 & 0,017872 & 4200 & U+ & $\mathrm{D}$ & 0,22 & 40 & 120 & 90 & 72 \\
\hline $\mathrm{SB} 2 \_3$ & $\mathrm{R}$ & 0 & 150 & 360 & 0 & 32,50 & 24,50 & 2,53 & $3,133 \mathrm{E}+04$ & 235000 & 0,017872 & 4200 & $\mathrm{U}$ & $\mathrm{D}$ & 0,22 & 40 & 120 & 90 & 52 \\
\hline SB3_2 & $\mathrm{R}$ & 0 & 150 & 360 & 0 & 32,50 & 24,50 & 2,53 & $3,133 \mathrm{E}+04$ & 235000 & 0,017872 & 4200 & $\mathrm{U}$ & $\mathrm{D}$ & 0,22 & 40 & 120 & 90 & 35 \\
\hline SB3_3 & $\mathrm{R}$ & 0 & 150 & 360 & 0 & 32,50 & 24,50 & 2,53 & $3,133 \mathrm{E}+04$ & 235000 & 0,017872 & 4200 & U+ & D & 0,22 & 40 & 120 & 90 & 54 \\
\hline A145 & $\mathrm{R}$ & 0 & 180 & 500 & 0 & 67,00 & 59,00 & 4,55 & $3,893 \mathrm{E}+04$ & 234000 & 0,019231 & 4500 & $\mathrm{~S}$ & $\mathrm{C}$ & 0,07 & 1 & 1,41 & 45 & 128 \\
\hline A245a & $\mathrm{R}$ & 0 & 180 & 500 & 0 & 71,00 & 63,00 & 4,75 & $3,961 \mathrm{E}+04$ & 234000 & 0,019231 & 4500 & $\mathrm{~S}$ & $\mathrm{C}$ & 0,11 & 1 & 1,41 & 45 & 138 \\
\hline
\end{tabular}


Miyajima et al. (2005)

\begin{tabular}{|c|c|c|c|c|c|c|c|c|c|c|c|c|c|c|c|c|c|c|c|}
\hline $\mathrm{A} 245 \mathrm{~b}$ & $\mathrm{R}$ & 0 & 180 & 500 & 0 & 53,00 & 45,00 & 3,80 & $3,628 \mathrm{E}+04$ & 234000 & 0,019231 & 4500 & $\mathrm{~S}$ & $\mathrm{C}$ & 0,11 & 1 & 1,41 & 45 & 186 \\
\hline $\mathrm{A} 245 \mathrm{~W}$ & $\mathrm{R}$ & 0 & 180 & 500 & 0 & 46,00 & 38,00 & 3,39 & $3,477 \mathrm{E}+04$ & 234000 & 0,019231 & 4500 & W & $\mathrm{C}$ & 0,11 & 1 & 1,41 & 45 & 219 \\
\hline $\mathrm{A} 245 \mathrm{Ra}$ & $\mathrm{R}$ & 0 & 180 & 500 & 0 & 67,00 & 59,00 & 4,55 & $3,893 \mathrm{E}+04$ & 234000 & 0,019231 & 4500 & $\mathrm{~S}$ & $\mathrm{C}$ & 0,11 & 1 & 1,41 & 45 & 187 \\
\hline $\mathrm{A} 245 \mathrm{Rb}$ & $\mathrm{R}$ & 0 & 180 & 500 & 0 & 47,00 & 39,00 & 3,45 & $3,500 \mathrm{E}+04$ & 234000 & 0,019231 & 4500 & $\mathrm{~S}$ & $\mathrm{C}$ & 0,11 & 1 & 1,41 & 45 & 132 \\
\hline A290a & $\mathrm{R}$ & 0 & 180 & 500 & 0 & 59,00 & 51,00 & 4,13 & $3,747 \mathrm{E}+04$ & 234000 & 0,019231 & 4500 & $\mathrm{~S}$ & $\mathrm{C}$ & 0,11 & 1 & 1 & 90 & 137 \\
\hline A290b & $\mathrm{R}$ & 0 & 180 & 500 & 0 & 52,00 & 44,00 & 3,74 & $3,608 \mathrm{E}+04$ & 234000 & 0,019231 & 4500 & $\mathrm{~S}$ & $\mathrm{C}$ & 0,11 & 1 & 1 & 90 & 179 \\
\hline A290W & $\mathrm{R}$ & 0 & 180 & 500 & 0 & 52,00 & 44,00 & 3,74 & $3,608 \mathrm{E}+04$ & 234000 & 0,019231 & 4500 & W & $\mathrm{C}$ & 0,11 & 1 & 1 & 90 & 248 \\
\hline A290WR & $\mathrm{R}$ & 0 & 180 & 500 & 0 & 46,00 & 38,00 & 3,39 & $3,477 \mathrm{E}+04$ & 234000 & 0,019231 & 4500 & W & $\mathrm{C}$ & 0,11 & 1 & 1 & 90 & 269 \\
\hline A345 & $\mathrm{R}$ & 0 & 180 & 500 & 0 & 71,00 & 63,00 & 4,75 & $3,961 \mathrm{E}+04$ & 234000 & 0,019231 & 4500 & $\mathrm{~S}$ & $\mathrm{C}$ & 0,17 & 1 & 1,41 & 45 & 215 \\
\hline B290 & $\mathrm{R}$ & 0 & 180 & 400 & 0 & 46,00 & 38,00 & 3,39 & $3,477 \mathrm{E}+04$ & 234000 & 0,019231 & 4500 & $\mathrm{~S}$ & $\mathrm{C}$ & 0,11 & 1 & 1 & 90 & 61 \\
\hline B390 & $\mathrm{R}$ & 0 & 180 & 400 & 0 & 46,00 & 38,00 & 3,39 & $3,477 \mathrm{E}+04$ & 234000 & 0,019231 & 4500 & S & $\mathrm{C}$ & 0,17 & 1 & 1 & 90 & 61 \\
\hline case2 & $\mathrm{R}$ & 0 & 340 & 440 & 0 & 29,90 & 21,90 & 2,35 & $3,056 \mathrm{E}+04$ & 253000 & 0,01913 & 4840 & W & D & 0,111 & 50 & 150 & 90 & 81,3 \\
\hline case 3 & $\mathrm{R}$ & 0 & 340 & 440 & 0 & 29,90 & 21,90 & 2,35 & $3,056 \mathrm{E}+04$ & 253000 & 0,01913 & 4840 & W & $\mathrm{D}$ & 0,111 & 75 & 150 & 90 & 122 \\
\hline case4 & $\mathrm{R}$ & 0 & 340 & 440 & 0 & 29,90 & 21,90 & 2,35 & $3,056 \mathrm{E}+04$ & 253000 & 0,01913 & 4840 & W & $\mathrm{D}$ & 0,111 & 87,5 & 150 & 90 & 132 \\
\hline case 5 & $\mathrm{R}$ & 0 & 340 & 440 & 0 & 29,90 & 21,90 & 2,35 & $3,056 \mathrm{E}+04$ & 253000 & 0,01913 & 4840 & W & $\mathrm{D}$ & 0,111 & 100 & 150 & 90 & 162 \\
\hline SS90* & $\mathrm{R}$ & 0 & 250 & 450 & 0 & 10,65 & 2,65 & 0,57 & $2,242 \mathrm{E}+04$ & 390000 & 0,007692 & 3000 & $\mathrm{~S}$ & D & 0,22 & 150 & 300 & 90 & 5 \\
\hline SS45 & $\mathrm{R}$ & 0 & 250 & 450 & 0 & 10,65 & 2,65 & 0,57 & $2,242 \mathrm{E}+04$ & 390000 & 0,007692 & 3000 & $\mathrm{~S}$ & $\mathrm{D}$ & 0,22 & 150 & 300 & 45 & 6 \\
\hline SSVA & $\mathrm{R}$ & 0 & 250 & 450 & 0 & 10,65 & 2,65 & 0,57 & $2,242 \mathrm{E}+04$ & 390000 & 0,007692 & 3000 & $\mathrm{~S}$ & $\mathrm{D}$ & 0,22 & 150 & 300 & 45 & 10 \\
\hline SF90 & $\mathrm{R}$ & 0 & 250 & 450 & 0 & 10,65 & 2,65 & 0,57 & $2,242 \mathrm{E}+04$ & 390000 & 0,007692 & 3000 & S & $\mathrm{C}$ & 0,22 & 1 & 1 & 90 & 17,5 \\
\hline US90* & $\mathrm{R}$ & 0 & 250 & 450 & 0 & 10,65 & 2,65 & 0,57 & $2,242 \mathrm{E}+04$ & 390000 & 0,007692 & 3000 & $\mathrm{U}$ & $\mathrm{D}$ & 0,22 & 150 & 300 & 90 & 0 \\
\hline US60 & $\mathrm{R}$ & 0 & 250 & 450 & 0 & 10,65 & 2,65 & 0,57 & $2,242 \mathrm{E}+04$ & 390000 & 0,007692 & 3000 & U & $\mathrm{D}$ & 0,22 & 150 & 300 & 60 & 16 \\
\hline
\end{tabular}




\begin{tabular}{|c|c|c|c|c|c|c|c|c|c|c|c|c|c|c|c|c|c|c|c|c|}
\hline & USVA & $\mathrm{R}$ & 0 & 250 & 450 & 0 & 10,65 & 2,65 & 0,57 & $2,242 \mathrm{E}+04$ & 390000 & 0,007692 & 3000 & $\mathrm{U}$ & $\mathrm{D}$ & 0,22 & 150 & 300 & 45 & 25 \\
\hline & USVA+ & $\mathrm{R}$ & 0 & 250 & 450 & 0 & 10,65 & 2,65 & 0,57 & $2,242 \mathrm{E}+04$ & 390000 & 0,007692 & 3000 & $\mathrm{U}+$ & $\mathrm{D}$ & 0,22 & 150 & 300 & 60 & 40 \\
\hline & US45+ & $\mathrm{R}$ & 0 & 250 & 450 & 0 & 10,65 & 2,65 & 0,57 & $2,242 \mathrm{E}+04$ & 390000 & 0,007692 & 3000 & $\mathrm{U}+$ & $\mathrm{D}$ & 0,22 & 150 & 300 & 45 & 31 \\
\hline & US90(2)* & $\mathrm{R}$ & 0 & 250 & 450 & 0 & 10,65 & 2,65 & 0,57 & $2,242 \mathrm{E}+04$ & 390000 & 0,007692 & 3000 & $\mathrm{U}$ & $\mathrm{D}$ & 0,22 & 150 & 300 & 90 & 0 \\
\hline & UF90 & $\mathrm{R}$ & 0 & 250 & 450 & 0 & 10,65 & 2,65 & 0,57 & $2,242 \mathrm{E}+04$ & 390000 & 0,007692 & 3000 & $\mathrm{U}$ & $\mathrm{C}$ & 0,22 & 1 & 1 & 90 & 30 \\
\hline & US45++ & $\mathrm{R}$ & 0 & 250 & 450 & 0 & 10,65 & 2,65 & 0,57 & $2,242 \mathrm{E}+04$ & 390000 & 0,007692 & 3000 & $\mathrm{U}+$ & $\mathrm{D}$ & 0,22 & 50 & 100 & 45 & 38,5 \\
\hline & US45+A & $\mathrm{R}$ & 0 & 250 & 450 & 0 & 10,65 & 2,65 & 0,57 & $2,242 \mathrm{E}+04$ & 390000 & 0,007692 & 3000 & U+ & $\mathrm{C}$ & 0,22 & 1 & 1,41 & 45 & 63,5 \\
\hline & UF45++B & $\mathrm{R}$ & 0 & 250 & 450 & 0 & 10,65 & 2,65 & 0,57 & $2,242 \mathrm{E}+04$ & 390000 & 0,007692 & 3000 & U+ & $\mathrm{C}$ & 0,22 & 1 & 1,41 & 45 & 72 \\
\hline & UF45++C & $\mathrm{R}$ & 0 & 250 & 450 & 0 & 10,65 & 2,65 & 0,57 & $2,242 \mathrm{E}+04$ & 390000 & 0,007692 & 3000 & U+ & $\mathrm{C}$ & 0,22 & 1 & 1,41 & 45 & 77 \\
\hline & US45++F & $\mathrm{R}$ & 0 & 250 & 450 & 0 & 10,65 & 2,65 & 0,57 & $2,242 \mathrm{E}+04$ & 390000 & 0,007692 & 3000 & $\mathrm{U}+$ & $\mathrm{D}$ & 0,22 & 150 & 225 & 45 & 87,85 \\
\hline & US45++E & $\mathrm{R}$ & 0 & 250 & 450 & 0 & 10,65 & 2,65 & 0,57 & $2,242 \mathrm{E}+04$ & 390000 & 0,007692 & 3000 & $\mathrm{U}+$ & $\mathrm{D}$ & 0,22 & 150 & 225 & 45 & 55,15 \\
\hline & US45+D & $\mathrm{R}$ & 0 & 250 & 450 & 0 & 10,65 & 2,65 & 0,57 & $2,242 \mathrm{E}+04$ & 390000 & 0,007692 & 3000 & $\mathrm{U}$ & $\mathrm{D}$ & 0,22 & 150 & 225 & 45 & 68,45 \\
\hline & WS45++ & $\mathrm{R}$ & 0 & 250 & 450 & 0 & 10,65 & 2,65 & 0,57 & $2,242 \mathrm{E}+04$ & 390000 & 0,007692 & 3000 & $\mathrm{~W}+$ & $\mathrm{D}$ & 0,22 & 50 & 100 & 45 & 19,5 \\
\hline Bousselham and Chaallal (2006) & DBS01L & $\mathrm{T}$ & 270 & 95 & 220 & 55 & 25,50 & 17,50 & 2,02 & $2,913 \mathrm{E}+04$ & 231000 & 0,015801 & 3650 & $\mathrm{U}+$ & $\mathrm{C}$ & 0,066 & 1 & 1 & 90 & 15,4 \\
\hline & DBS02L & $\mathrm{T}$ & 270 & 95 & 220 & 55 & 25,50 & 17,50 & 2,02 & $2,913 \mathrm{E}+04$ & 231000 & 0,015801 & 3650 & $\mathrm{U}+$ & $\mathrm{C}$ & 0,132 & 1 & 1 & 90 & 13,8 \\
\hline & DBS11L & $\mathrm{T}$ & 270 & 95 & 220 & 55 & 25,50 & 17,50 & 2,02 & $2,913 \mathrm{E}+04$ & 231000 & 0,015801 & 3650 & $\mathrm{U}+$ & $\mathrm{C}$ & 0,066 & 1 & 1 & 90 & 12,7 \\
\hline & DBS12L & $\mathrm{T}$ & 270 & 95 & 220 & 55 & 25,50 & 17,50 & 2,02 & $2,913 \mathrm{E}+04$ & 231000 & 0,015801 & 3650 & U+ & $\mathrm{C}$ & 0,132 & 1 & 1 & 90 & 17 \\
\hline & SBS01L & $\mathrm{T}$ & 270 & 95 & 220 & 55 & 25,50 & 17,50 & 2,02 & $2,913 \mathrm{E}+04$ & 231000 & 0,015801 & 3650 & U+ & $\mathrm{C}$ & 0,066 & 1 & 1 & 90 & 23,2 \\
\hline & SBS02L & $\mathrm{T}$ & 270 & 95 & 220 & 55 & 25,50 & 17,50 & 2,02 & $2,913 \mathrm{E}+04$ & 231000 & 0,015801 & 3650 & U+ & $\mathrm{C}$ & 0,132 & 1 & 1 & 90 & 32,4 \\
\hline & SBS11L & $\mathrm{T}$ & 270 & 95 & 220 & 55 & 25,50 & 17,50 & 2,02 & $2,913 \mathrm{E}+04$ & 231000 & 0,015801 & 3650 & U+ & $\mathrm{C}$ & 0,066 & 1 & 1 & 90 & 2,8 \\
\hline & SBS12L & $\mathrm{T}$ & 270 & 95 & 220 & 55 & 25,50 & 17,50 & 2,02 & $2,913 \mathrm{E}+04$ & 231000 & 0,015801 & 3650 & U+ & $\mathrm{C}$ & 0,132 & 1 & 1 & 90 & 12,2 \\
\hline
\end{tabular}




$\begin{array}{ccccccccccccccccccccccc}\text { 2S_4M(1) } & \mathrm{T} & 450 & 180 & 400 & 100 & 38,10 & 30,10 & 2,90 & 3,286 \mathrm{E}+04 & 240000 & 0,015 & 3600 & \mathrm{U} & \mathrm{D} & 0,176 & 60 & 180 & 90 & 4,38 \\ \text { 2S_7M(1) } & \mathrm{T} & 450 & 180 & 400 & 100 & 38,10 & 30,10 & 2,90 & 3,286 \mathrm{E}+04 & 240000 & 0,015 & 3600 & \mathrm{U} & \mathrm{D} & 0,176 & 60 & 114 & 90 & 12,78 \\ \text { 2S_7M(2) } & \mathrm{T} & 450 & 180 & 400 & 100 & 38,10 & 30,10 & 2,90 & 3,286 \mathrm{E}+04 & 240000 & 0,015 & 3600 & \mathrm{U} & \mathrm{D} & 0,352 & 60 & 114 & 90 & 39,78 \\ \text { 4S_4M(1) } & \mathrm{T} & 450 & 180 & 400 & 100 & 41,00 & 33,00 & 3,09 & 3,359 \mathrm{E}+04 & 240000 & 0,015 & 3600 & \mathrm{U} & \mathrm{D} & 0,176 & 60 & 180 & 90 & 27,6 \\ \text { 4S_7M(1) } & \mathrm{T} & 450 & 180 & 400 & 100 & 41,00 & 33,00 & 3,09 & 3,359 \mathrm{E}+04 & 240000 & 0,015 & 3600 & \mathrm{U} & \mathrm{D} & 0,176 & 60 & 114 & 90 & 30,96 \\ \text { UW90 } & \mathrm{R} & 0 & 200 & 210 & 0 & 29,30 & 21,30 & 2,31 & 3,037 \mathrm{E}+04 & 230000 & 0,014913 & 3430 & \mathrm{U} & \mathrm{C} & 0,165 & 1 & 1 & 90 & 19,3 \\ \text { A10_M } & \mathrm{R} & 0 & 150 & 300 & 0 & 49,20 & 41,20 & 3,58 & 3,548 \mathrm{E}+04 & 390000 & 0,007692 & 3000 & \mathrm{U} & \mathrm{D} & 0,334 & 25 & 190 & 90 & 10,83 \\ \text { A12_M } & \mathrm{R} & 0 & 150 & 300 & 0 & 49,20 & 41,20 & 3,58 & 3,548 \mathrm{E}+04 & 390000 & 0,007692 & 3000 & \mathrm{U} & \mathrm{D} & 0,334 & 25 & 95 & 90 & 31,52 \\ \text { B10_M } & \mathrm{R} & 0 & 150 & 150 & 0 & 56,20 & 48,20 & 3,97 & 3,693 \mathrm{E}+04 & 390000 & 0,007692 & 3000 & \mathrm{U} & \mathrm{D} & 0,334 & 25 & 80 & 90 & 18,56 \\ \text { B12_M } & \mathrm{R} & 0 & 150 & 150 & 0 & 56,20 & 48,20 & 3,97 & 3,693 \mathrm{E}+04 & 390000 & 0,007692 & 3000 & \mathrm{U} & \mathrm{D} & 0,334 & 25 & 40 & 90 & 33,65\end{array}$

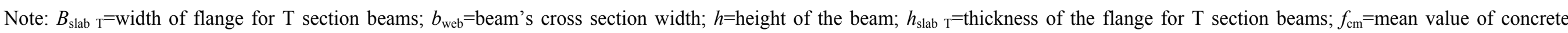

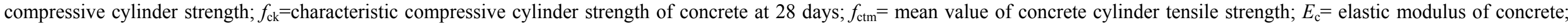

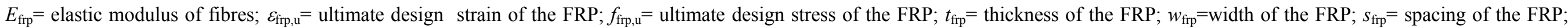

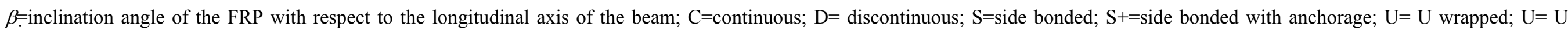
wrapped with anchorage; $\mathrm{W}=$ fully wrapped; $\mathrm{W}=$ fully wrapped with anchorage; $\mathrm{V}_{\text {frp }}=$ contribution of the FRP to the shear capacity of the beam. 